\title{
Cazadores-recolectores y el paisaje en Serranópolis, GoiÁs, Brasil
}

\author{
Julio Cezar Rubin de Rubina, Sibeli Aparecida Viana ${ }^{b}$, Rosiclér Theodoro da Silvac,

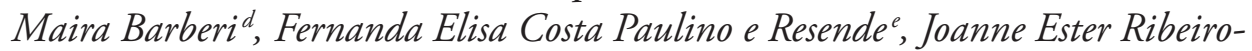 \\ Freitas $f$, Mariana Garcia de Souzag, Eloah Vargas Ribeiro ${ }^{h}$
}

\begin{abstract}
Resumen
Este artículo analiza algunos datos resultantes de investigaciones pioneras y posteriores en Serranópolis, Goiás, Brasil, abordando temas como el paisaje, la movilidad, la territorialidad, la distribución de sitios con representaciones rupestres, material lítico, acción antrópica y procesos naturales como elementos impactantes en los sitios arqueológicos. El recorte temporal establecido cubre las ocupaciones humanas de los grupos de cazadores-recolectores afiliados a la Tradición Itaparica (fase Paranaíba) y Tradición Serranópolis (fase Serranópolis), del Holoceno Temprano a Medio. En la perspectiva adoptada, a los datos publicados por Schmitz y colaboradores, entre los años 1980 y 2000, para los seis núcleos de sitios arqueológicos establecidos en la región, se insertaron los resultados de las investigaciones realizadas entre los años 2000 y 2020. Desde una visión multidisciplinaria de base de la investigación, el paisaje es el tema principal, el elemento conductor, analizado bajo la perspectiva de la arqueología del paisaje. El texto señala ciertos temas que deben ser continuamente retomados utilizando técnicas de análisis actualizadas, así como aquellas que deben desarrollarse, especialmente excavaciones de nuevos sitios y un enfoque especifico en relación con el paisaje y la producción de datos e informaciones para el análisis bajo la perspectiva de la geoarqueología.
\end{abstract}

Palabras clave: arqueología, Holoceno, geoarqueología, arqueología del paisaje

Abstract

\section{HUNTERS-GATHERERS AND THE LANDSCAPE IN SERRANÓPOLIS, GOIÁS, BRAZIL}

This paper discusses data from the pioneering and the latest research in Serranópolis, Goiás, Brazil. It focuses on subjects such as landscape, mobility, territoriality, distribution of rock art sites, lithic material, anthropic action, and natural processes as elements that impact archaeological sites. The approach includes the hunter-gathering groups from the Itaparica (Paranaiba Phase) and Serranópolis (Serranópolis Phase) Traditions from Upper to Middle Holocene, which are characterized by their set of lithic artifacts. Therefore, some data resulting from research that took place between 2000 and 2020 by several researches were included in the previous study from 1980 to 2000 by Schmitz and his crew. The key element is the landscape analysed within a multidsciplinary approach through the Landscape Archaeology. This paper emphasizes some subjects that must be reanalyzed through current techniques and sustains that new excavations

a https://orcid.org/0000-0001-9789-2559 Pontifícia Universidade Católica de Goiás. rubin@pucgoias.edu.br Pesquisador bolsista do CNPq, nível 2

b https://orcid.org/0000-0001-6609-8192 Pontifícia Universidade Católica de Goiás. sibeli@pucgoias.edu.br Pesquisadora bolsista do CNPq, nível 2 .

c https://orcid.org/0000-0003-0449-1663 Pontifícia Universidade Católica de Goiás. silva.rosicler@gmail.com

d https://orcid.org/0000-0003-0484-0237 Pontifícia Universidade Católica de Goiás. barberimaira@gmail.com

e https://orcid.org/0000-0002-9496-5414 CLAM Engenharia, Meio Ambiente, Arqueologia e Patrimônio Cultural. fernandaecosta@gmail.com

f https://orcid.org/0000-0002-7680-2910 Universidade Federal de Goiás. ribeiro_freitas@discente.ufg.br

g https://orcid.org/0000-0002-7100-0775 Pontifícia Universidade Católica de Goiás. marigarcia2806@gmail.com

h https://orcid.org/0000-0001-9164-1353 Pontifícia Universidade Católica de Goiás. eloh3@icloud.com

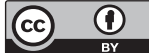


need to take place with a special attention to the relation between the landscape and the data developed under a geoarqueological point of view.

Keywords: Archaeology, Holocene, geoarchaeology, landscape archaeology

\section{Introducción}

El Complejo Arqueológico de Serranópolis se destaca en la arqueología brasileña en relación a la cultura material, cronología, estratigrafía, representaciones rupestres y el buen estado de conservación de las capas ocupacionales de los sitios. Schmitz y sus colaboradores entre los años 1970 y 1990 evidenciaron 53 sitios arqueológicos, de los cuales 27 fueron investigados, ubicados principalmente en abrigos rocosos en la cuenca del río Verde (Fig. 1). De los seis núcleos establecidos por los autores, se destacan el Núcleo A (Gruta do Diogo) con el sitio GO-JA-01, el Núcleo D con el sitio GO-JA-03 (Manoel Braga) y Núcleo F con el sitio GO -JA-14 (Urubu), que presentó, hasta el momento, la fecha más antigua de la región, correspondiente a 10,740 \pm 85 AP (SI-3177) (Tabla 1).

Los resultados de las investigaciones están publicados en Schmitz (1980, 1987), Schmitz y Barbosa (1985), Schmitz et al. (1989, 1997, 2004), entre otros. En las últimas décadas, las investigaciones han continuado presentando datos importantes en la región, principalmente en relación a los sitios a cielo abierto, el paisaje, las tecnologías de producción de los objetos y las cronologías de los sitios (Souza 2005; Rubin y Silva 2006; Griphus Consultoria 2006, 2007; Lourdeau 2010; Nascimento 2012; Nogueira 2013, 2015; Ramos 2016; Viana 2016; Rubin 2017; Rubin et al. 2016, 2017, 2018; Resende 2017; Andrade 2018; Araujo 2018; Rodet et al. 2019; Ramos y Viana 2019; Procedino 2019; Carvalho 2019; Silva 2019; Resende et al. 2019; Oliveira 2019; Fonseca 2019; Silva et al. 2020; Fernandes et al. e.p.; Viana y Hoeltz e.p.; Souza 2020).

El contexto geoarqueológico del área de estudio resulta de la interacción entre areniscas de la Formación Botucatu, depositadas en ambiente desértico durante el Jurásico y derrames de lavas basálticas relacionadas a la Formación Serra Geral y los cuales, en contacto con las areniscas dieron origen, a través de procesos de metamorfismo de contacto, a areniscas silicificadas que constituyen la materia prima básica para la industria lítica encontrada en los sitios arqueológicos (Pereira et al. 2012; Almeida et al. 2012).

Durante el Cenozoico, la alternancia de fases calientes y húmedas con fases calientes y secas dieron origen a procesos de meteorización de carácter químico y físico los cuales, actuando sobre las rocas, fueron responsables por la compartimentación del relieve, con superficies donde se destacan mesetas y depresiones suave onduladas, que constituyen en la región la depresión interplanáltica del río Verde, con cotas de 500 hasta 700 msnm (Mamede 1996; Vasconcelos 1996; Bartorelli 2012).

Con respecto al origen de los abrigos, la secuencia de areniscas y basaltos presenta también sistemas de fracturamientos horizontales, subhorizontales, verticales y subverticales, además de estratificaciones plano paralelas y cruzadas en las areniscas, que constituyen planos de discontinuidad y de fragilidad que favorecen la percolación de soluciones. La asociación de estos planos con los niveles más resistentes, representados por areniscas silicificadas, cuyo cimento resultante de la diagénesis es la sílice, más resistente a la meteorización, y a los niveles más friables, resultan en la formación de los abrigos que componen el Complejo Arqueológico de Serranópolis y que se ubican entre 100 y 200 metros de altitud sobre el valle del río Verde (Schmitz et al. 1989; Procedino 2019). 


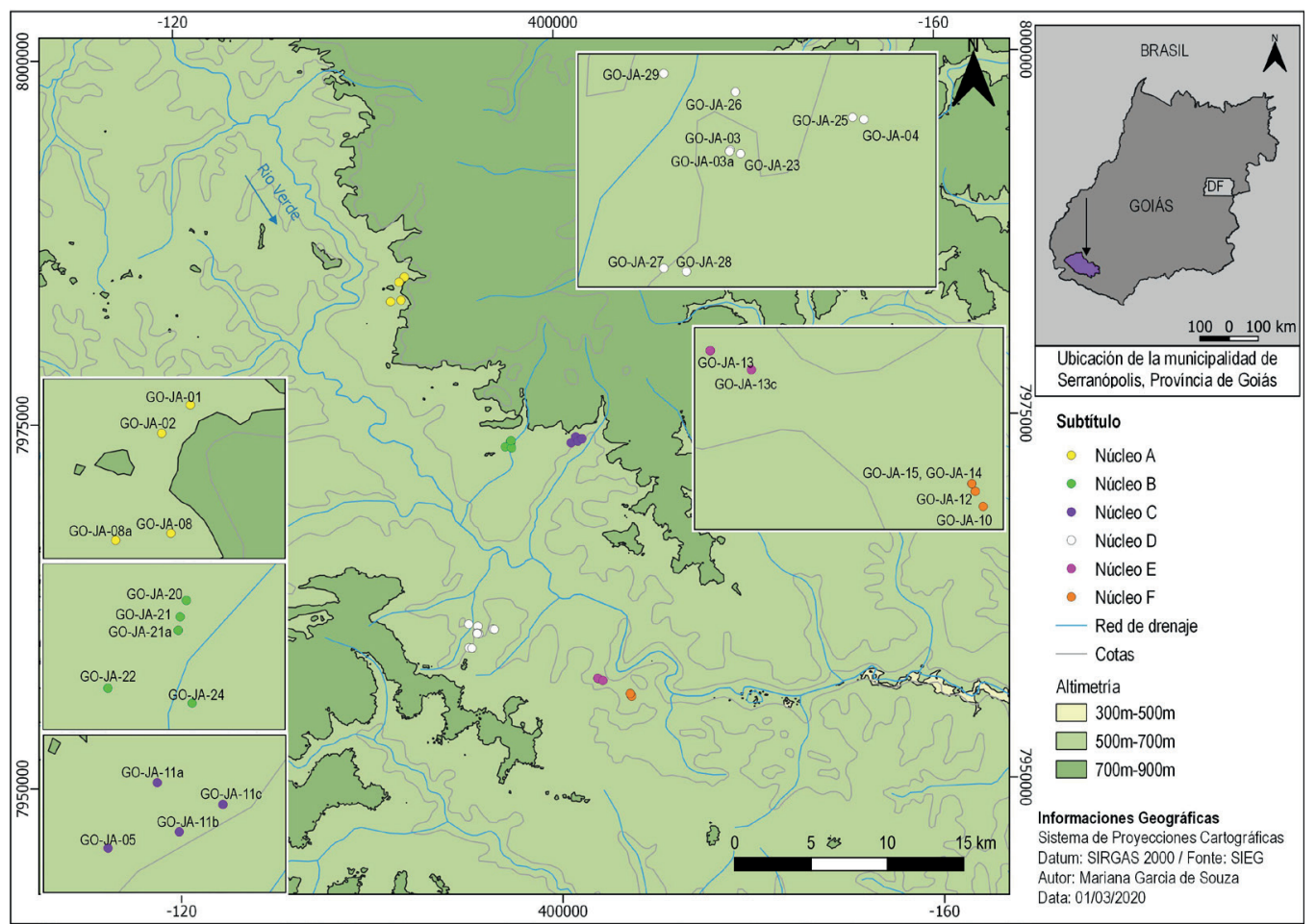

Figura 1. Distribución de los seis núcleos de sitios arqueológicos del Complejo de Serranópolis (fuente: Souza (2020) adaptado de Schmitz et al. (2004) y Lima (2016)).

Los procesos de meteorización también fueron responsables del desarrollo de un neossolo ${ }^{1}$ quartzarênico en áreas donde afloran las areniscas, muy friable y permeable, o de un neossolo litólico, en la parte superior de los abrigos donde predominan las areniscas silicificadas. La meteorización de los basaltos resultó en el desarrollo de latossolos ${ }^{2}$ rojos amarillentos, normalmente profundos, estructurados, y que consisten básicamente de minerales de arcilla y óxidos de hierro y aluminio que le dan al sedimento el color rojizo (Reatto et al. 2008; Scopel et al. 2010).

El clima predominante en la región se define como semihúmedo con precipitación anual de alrededor de 1700 milímetros distribuidos de manera desigual y temperatura mediana anual sobre $20{ }^{\circ} \mathrm{C}$. En este contexto se destacan dos estaciones bien definidas representadas por un invierno seco de abril a septiembre, y un verano caliente y húmedo de octubre a marzo que presentan en los meses de noviembre, diciembre y enero medias mensuales de precipitación de 200 milímetros (Silva et al. 2008).

El régimen climático asociado a suelos profundos y la acción de elementos como el fuego, constituyeron aspectos fundamentales en la implementación de vegetación del bioma cerrado ${ }^{3}$, caracterizado por una gran biodiversidad y tasa de endemismo de plantas y que presenta en la región diversas fitofisionomias ${ }^{4}$ (Ribeiro y Walter 2008).

En áreas donde afloran los basaltos, predominan las fitofisionomias de las formaciones florestales representadas por cerradão (ver nota 4) y por mata seca sempre-verde, siendo que esta última ocurre también en áreas de neossolos quartzarênicos, donde la humedad está más preservada en función de la presencia de pequeñas depresiones en el terreno, que se forman entre los abrigos o delante de las grandes paredes rocosas. En otras áreas de suelos arenosos, predominan la vegetación del tipo sabanas representadas por el cerrado en el sentido estricto y el cerrado rupestre, sobre los abrigos donde afloran las areniscas silicificadas (Ribeiro y Walter 2008). 


\begin{tabular}{|c|c|c|c|c|c|}
\hline 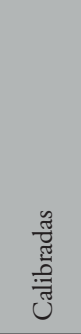 & 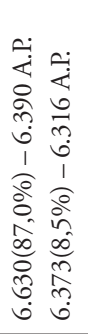 & 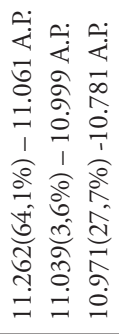 & 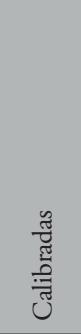 & 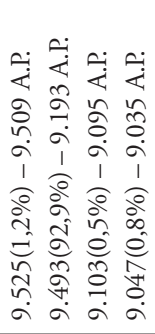 & 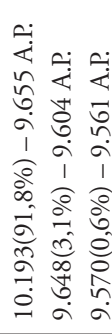 \\
\hline 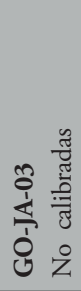 & 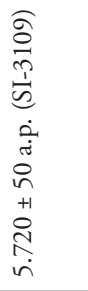 & 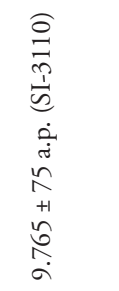 & 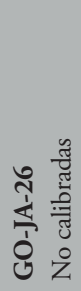 & 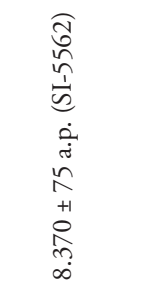 & 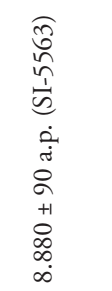 \\
\hline 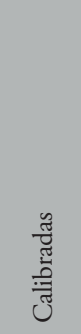 & 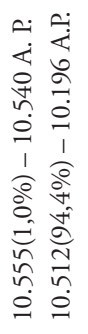 & 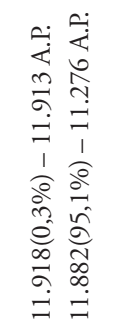 & 胥 & \multicolumn{2}{|c|}{ 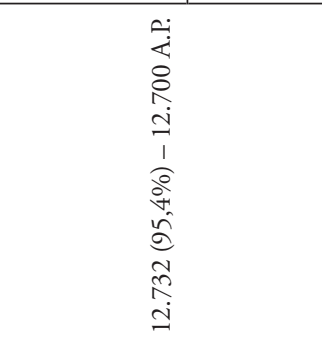 } \\
\hline 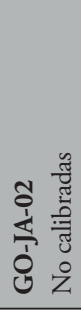 & 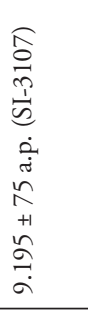 & 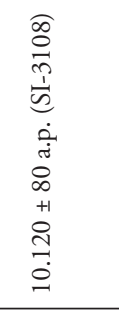 & 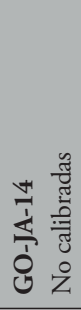 & \multicolumn{2}{|c|}{ 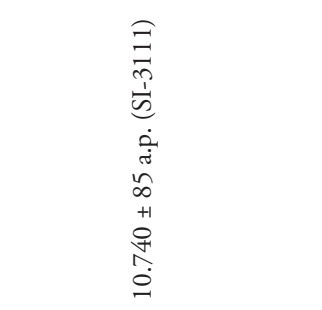 } \\
\hline 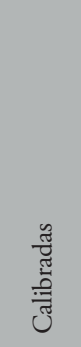 & 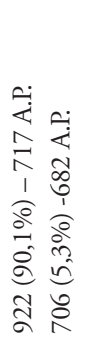 & 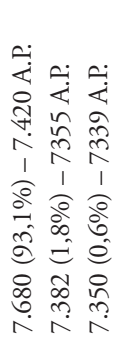 & 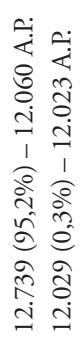 & 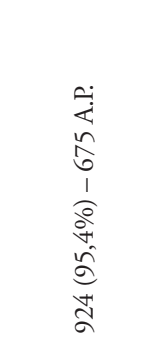 & 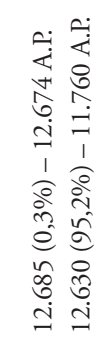 \\
\hline 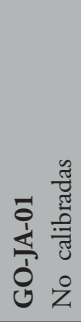 & 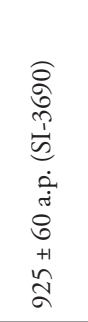 & 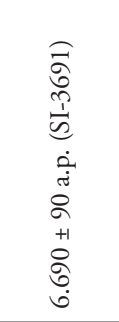 & 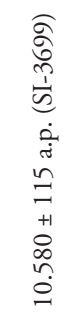 & 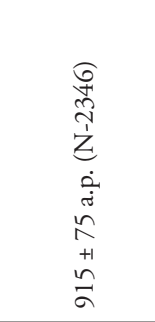 & 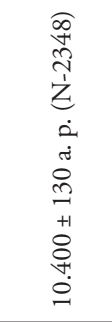 \\
\hline
\end{tabular}


Cabe señalar, sin embargo, que actualmente el área constituye una región de tensión ecológica con el avance de extensos cultivos de cańa o de pastizales sobre la vegetación natural, lo que resulta en fuertes procesos de meteorización, principalmente en áreas de ocurrencia de suelos arenosos friables, con el desarrollo de cárcavas, pérdidas de suelos y consecuente colmatación de arroyos y ríos.

El contexto paleoambiental de áreas de cerrados ha sido presentado a partir de datos provenientes de análisis palinológicas de sedimentos depositados en lagos y terrazas aluviales. En la región de Serranópolis las fechas más antiguas de ocupación humana se sitúan alrededor de 12,732 cal. AP, pero los datos paleoecológicos de las tierras bajas tropicales en áreas de cerrados se inician cerca de 44,000 cal. AP los cuales provienen de la región de la cuenca hidrográfica del río Meia Ponte, en la parte central de la provincia de Goiás, posibilitando una visión de la evolución del paisaje a partir del Pleistoceno Tardío en el intervalo MIS 3 (Marine Isotope Stage) (entre c. 57,000 y 29,000 ańos AP) (Barberi y Lima-Ribeiro 2008; Do Carmo et al. 2003; Rubin 2003).

Las localidades con datos palinológicos comprenden áreas con vegetación actual de los cerrados ubicados en las provincias de Goiás, Minas Gerais y Maranhão y muestran un patrón similar para áreas del Pleniglacial Medio, relacionado al MIS 3 (entre 57,000 y 29,000 AP), con predominio de condiciones más húmedas que las actuales, con fluctuaciones de temperatura, alcanzando valores similares a los actuales. En los diagramas palinológicos de esta fase predominan elementos botánicos de bosques con alta biodiversidad y la presencia ocasional de elementos de clima frío ( $v$.g. Ilex, Podocarpus, Hedyosmum), además de la ocurrencia de veredas ${ }^{5}$ representados por el elemento Mauritia (ver nota 5) en intervalos en que la temperatura se presentaba similar a la actual (Barberi 2001; Barberi y Lima-Ribeiro 2008; Ledru 2002; Rubin et al. 2011).

Desde el inicio del Pleniglacial Superior, alrededor de 28,000 AP, o en la fase MIS 2 (entre 29,000 y 14,000 años AP), se verifican aún condiciones oscilatorias en la humedad, pero con una tendencia general a la baja, asociada a una fuerte caída de temperatura que alcanza su máximo entre 21,000 y 18,000 AP, lo cual es causante, en áreas de cerrados, de la retracción de la vegetación arbórea, expansión de la vegetación abierta, ausencia de veredas y cambios en la dinámica superficial, con interrupciones en la deposición de secuencias orgánicas y evidencia de exposición del suelo y sedimentación detrítica (Salgado-Labouriau et al. 1997; Barberi et al. 2000; Barberi 2001; Ledru 2002; Barberi y Lima Ribeiro 2008).

Los datos de diferentes ubicaciones indican que las fuertes caídas de precipitación y temperatura fueron un fenómeno regional durante la etapa MIS 2 en las áreas nucleares de los cerrados, pero no ocurrieron de manera sincrónica. Los registros muestran que existe una tendencia a retrasar el inicio de esta fase en las latitudes mayores, lo que se atribuye a aspectos regionales como la forma del continente, el posicionamiento de las sierras y las características de las localidades como la altitud, configuración geomorfológica, microclimas específicos y tipos de suelos, que podrían constituir elementos para variaciones en la respuesta de la vegetación a fenómenos climáticos de gran escala, como la glaciación que ocurrió en esta etapa con cambios significativos en los Andes y en el hemisferio norte (Salgado-Labouriau et al.1997; Ledru et al. 2006; Barberi y Lima-Ribeiro 2008).

A partir del Glacial Tardío en el Pleistoceno Superior (c. 13,000 AP) y el inicio del Holoceno, en la fase MIS 1 (14,000 años AP) con el final de la glaciación de Würm/Wisconsin (11,000 AP), se registran nuevos cambios climáticos para las tierras bajas tropicales con la ocurrencia actual de los cerrados, evidenciada por un cambio significativo en los diagramas palinomorfos, donde predominan los elementos botánicos propios del bioma cerrado. La tendencia al aumento de la temperatura está asociada a un aumento de la humedad, pero de forma oscilatoria, probablemente con fases donde las estaciones secas habrían sido más largas. Se evidencian condiciones de humedad más constantes y temperaturas más elevadas en las zonas de los cerrados, por la implantación o retorno de las veredas, lo cual ocurre entre 8000 y 6000 AP (Barberi 2001; Barberi y Lima-Ribeiro 2008; Rubin et al. 2011). 
Un aspecto relevante en el análisis de datos paleoecológicos, provenientes de áreas de cerrado durante el Holoceno, es la presencia de fases más húmedas o secas que en la actualidad en las tierras bajas tropicales. En las diferentes localizaciones que presentan análisis palinológicos, esto no ocurre de forma sincrónica, por eso no es posible establecer correlaciones regionales respecto a las condiciones climáticas, lo que sugiere un mayor peso de los parámetros locales en la configuración de la vegetación y el paisaje. Sin embargo, todas las localidades presentan una dominancia de los taxones de cerrados y una disminución en la diversidad en relación al conjunto presente durante la humedad máxima en el Pleniglacial Medio o en la fase MIS 3 (Barberi et al.2000; Barberi 2001; Barberi y Lima-Ribeiro 2008).

En general, para todas las tierras bajas tropicales con ocurrencia del bioma cerrado, la instalación de condiciones similares a las actuales, responsables por el patrón actual de distribución de la vegetación, sucede efectivamente alrededor de 2000 AP. Este hecho también muestra la rapidez con la que la vegetación responde al cambio climático y, en consecuencia, a la interferencia antrópica (Barberi 2001; Barberi y Lima-Ribeiro 2008; Rubin et al. 2011).

Aunque los fenómenos puedan constituir aspectos globales, no son sincrónicos y se puede observar que las diferencias en la respuesta de cada área a los cambios paleoclimáticos, no solo con respecto a la cronología, sino también en relación con los cambios en el paisaje, también están influenciadas por las características locales, lo que exige trabajos detallados en áreas con estudios arqueológicos y cuidado en la extrapolación de datos regionales de carácter paleoclimático.

En este contexto, el mosaico actual de las áreas de cerrados, con la diversidad de fitofisionomias presentes y los recursos disponibles relacionados con cada fitofisionomia, constituye una respuesta a la interacción entre parámetros físicos globales y locales, asociados a la interacción humana con grupos prehistóricos e históricos.

El potencial ocupacional de la región de Serranópolis presenta actualmente una vocación agropecuaria, la principal actividad en la provincia de Goiás, generadora de empleos e impuestos. Sin embargo, estas son actividades impactantes que, directa o indirectamente, afectan los sitios arqueológicos, según lo abordado por Rubin et al. (2016, 2017), Carvalho (2019), Moura (2019), Resende et al. (2019) y Souza (2020). Con relación a los impactos, la definición de sitio arqueológico impregna las discusiones, tema analizado por varios autores como Sanjuán (2005), Barreto (2010), Bicho (2011) y Campos (2019).

El contexto arqueológico de Serranópolis se discute considerando el sitio arqueológico como un artefacto (Barreto 2010: 78); el paisaje como resultado de la interacción humana con el medio ambiente (Criado Boado 1999: 5); y el concepto de sitio arqueológico basado en parte de la definición adoptada por Feder (2009: 42): «where humans lived, worked, or carried out a task» ${ }^{6}$.

Irrefutable a la investigación arqueológica es la comprensión del entorno de los sitios; es decir, del paisaje donde se integran los sitios. Según Knapp y Ashmore (1999), la inserción del paisaje como parte de la investigación arqueológica siempre ha sido una preocupación de los expertos. Sin embargo, las relaciones entre el paisaje y la arqueología (que se construyó a lo largo de los años) han adquirido una dimensión importante en el contexto del pensamiento procesual y posprocesual.

Con base en la influencia de la arqueología procesual y funcionalista en el estudio del paisaje, se puede ver que esta instituyó una concepción del espacio desde una perspectiva contemporánea; es decir, predominando el análisis de los componentes económicos y determinísticos, con respecto a la maximización de recursos y esfuerzos. De acuerdo con Villafañez (2012: 124) «Esta idea del espacio ha propiciado perspectivas reduccionistas, donde el hombre es un ser ecosistémico y el espacio es visto como un elemento empírico y mediable». Todavía, a partir de la década de 1990, autores como Criado-Boado (1999) y Branton (2009) insertaron en el estudio del paisaje percepciones más holísticas, permitiendo la expansión de paradigmas.

De hecho, el paisaje ha adquirido varios significados a lo largo del tiempo, yendo más allá de un simple análisis de sus componentes físicos, a la inserción de los individuos como parte integrante 
y modificadores de su realidad. La percepción de un contexto simbólico como una parte importante del concepto de paisaje está relacionada, principalmente, con la arqueología posprocesual. Actualmente, se entiende que la arqueología del paisaje busca comprender el espacio físico, entrelazado en un espacio social, humanizado, económico, agrario, de vivienda, político y territorial, donde los comportamientos simbólicos también están presentes (Lino 2012).

Goldberg y Macphail (2006) presentan procedimientos de análisis del paisaje desde una perspectiva geoarqueológica, abordando suelos, sistemas fluviales, dinámica superficial, acción eólica, ambientes costeros, cuevas y abrigos. La utilización de la geoarqueología para los estudios del paisaje también es destacada en French (2003), Holliday (2004), Villagran (2010), Giannini et al. (2010), Castińeira et al. (2013), Tchilinguirián et al. (2016), Peña Monné et al. (2016), SampietroVattuone y Peña Monné (2016, 2019), Bermúdez (2017), entre tantos.

El objetivo de este artículo es discutir algunos temas relacionados con el paisaje en el contexto de los sitios de Serranópolis, bajo la perspectiva de la arqueología del paisaje, así como abordar temas relacionados con el territorio, la territorialidad, movilidad y otras variables que pueden ser utilizadas a futuro, en el análisis del paisaje desde una perspectiva geoarqueológica. El recorte adoptado para Serranópolis en este artículo cubre los grupos cazadores-recolectores de la tradición Itaparica (fase Paranaíba) y la Tradición Serranópolis (fase Serranópolis).

\section{Materiales y métodos}

El artículo se basa en el análisis de algunos de los resultados de las investigaciones desarrolladas por Schmitz et al. (1989, 1997, 2004) y en los resultados obtenidos en investigaciones posteriores, principalmente aquellas realizadas entre 2016 y 2019 (Ramos 2016; Viana 2016; Rubin 2017; Rubin et al. 2016, 2017, 2018; Resende 2017; Andrade 2018; Araujo 2018; Rodet et al. 2019; Ramos y Viana 2019; Procedino 2019; Carvalho 2019; Silva 2019; Resende et al. 2019; Oliveira 2019; Fonseca 2019; Silva et al. 2020; Fernandes et al. e.p.; Viana y Hoeltz e.p.; Souza 2020), las cuales no incluyeron nuevas excavaciones.

La figura 1 presenta los seis núcleos definidos por Schmitz et al. (2004), con los sitios investigados, y es la base para el desarrollo de las discusiones. En ella es posible verificar la distribución espacial de los sitios arqueológicos, insertados en un área actualmente utilizada por la agricultura, la ganadería y la industria de derivados del alcohol, con segmentos de suelo expuestos, procesos de erosión en pleno desarrollo y otros en etapas iniciales. Considerando la distribución de los sitios y desde la perspectiva de Feder (2009), la acción antrópica tuvo un fuerte impacto en la región y en los sitios, resultando en un paisaje antropizado, como lo abordaron Rubin et al. (2017) en relación con el sitio GO-JA-13, presentando medidas básicas de mitigación. La figura 2 presenta fotografías de algunos de los sitios arqueológicos en Serranópolis.

Para discutir estos casos fue necesario agrupar los Núcleos B y C en solo uno, así como los Núcleos E y F, debido a la proximidad. También se estableció un sitio central para cada núcleo (Souza 2020). Para el Núcleo A, se eligió el sitio GO-JA-01, dado que Schmitz et al. $(1989,2004)$ mostraron una larga secuencia de ocupaciones, desde el Holoceno temprano (11,700 - 8200 AP) hasta el Holoceno tardío (4200 AP), y para cada período hubo un uso intenso del área del abrigo rocoso, que sostendría un número relevante de individuos (Schmitz et al. 1989).

Para el Núcleo B/C, se consideró el sitio GO-JA-20 (perteneciente al Núcleo B), seleccionado por la gran cantidad de artefactos líticos recolectados en las intervenciones realizadas por Schmitz et al. $(1989,2004)$ en comparación con los otros sitios del área, además de la presencia de dos entierros humanos. En el Núcleo D, se eligió el sitio GO-JA-03 debido a la gran cantidad de artefactos líticos, cerámicos, pinturas y grabados en las paredes del abrigo rocoso. En el Núcleo E/F se consideró el sitio GO-JA-14 (originalmente del Núcleo F) igualmente por la cantidad relevante 

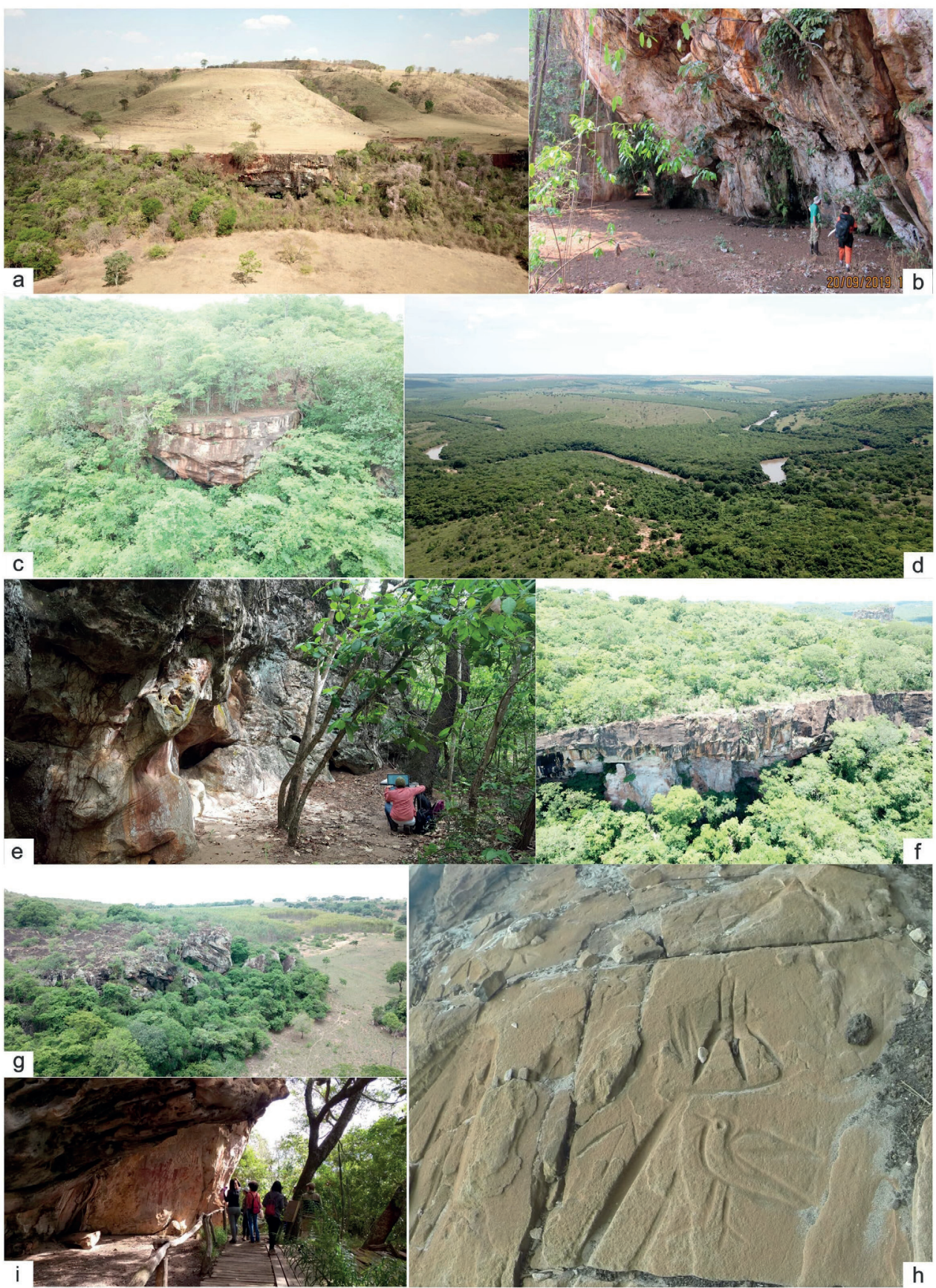

Figura 2. Fotografias de algunos sitios arqueológicos: a) vista parcial del GO-JA-01; b) GO-JA-02; c) vista parcial del GO-JA-08; d) vista parcial del Núcleo F; e) GO-JA-26; f) GO-JA-04; g) vista del Núcleo F; h) grabado del GO-JA-27; i) GO-JA-03 (fuente: acervo fotográfico del Proyecto Serranópolis). 
de artefactos líticos y la presencia de pinturas y grabados, además de un número significativo de enterramientos humanos, en comparación con otros sitios del área (Souza 2020).

En relación con el territorio, la territorialidad y la movilidad, se utilizaron Willey (1953), Cashdan (1983), Little (2002) y Rogge (2004). Para el paisaje, las referencias son de Criado-Boado (1999) y Branton (2009). En cuanto a la perspectiva de los grupos con subsistencia basados en la caza, la recolección y la pesca como transformadores del paisaje, se adoptó la perspectiva de los depósitos antropogénicos (Oliveira 1990,1994; Rubin 2003; Oliveira y Monticeli 2018) como línea de análisis.

Las informaciones disponibles en Schmitz et al. (1989, 1997, 2004) y las producidas entre el 2016 y 2019, fueron analizada e interpretada, lo que resultó en dos grupos: las producidas por las excavaciones pioneras y las nuevas. En relación a las primeras, revelaron un importante conjunto de información, especialmente en relación a la cultura material, representaciones rupestres y cronologías. Las limitaciones están relacionadas especialmente con la estratigrafía y el paisaje. Cabe señalar que Bitencourt (2008) establece correlaciones que involucran las fases de ocupaciones de los sitios GO-JA-01, GO-JA-03 y GO-JA-26, abordando aspectos sedimentarios y geoquímicos, destacando el uso de clases texturales y valores de $\mathrm{P}_{2} \mathrm{O}_{5}$. Es un trabajo que complementa las informaciones en relación a Schmitz et al. (2004), pero es necesario extenderlo a otros sitios, especialmente cuando el objetivo es el paisaje desde la perspectiva de la geoarqueología.

Con relación a nuevas investigaciones, las aproximaciones se centraron en el paisaje, discutiendo la apropiación y construcción, aspectos simbólicos y reanálisis de parte del material lítico del sitio GO-JA-01. Como se destacó anteriormente, este conjunto de información se analizó desde la arqueología del paisaje.

El ejercicio de trabajar con el conjunto de información sobre el paisaje permitió un paralelismo entre las perspectivas de la geoarqueología y la arqueología del paisaje, que inicialmente se puso en duda en cuanto a practicidad, pero que resultó ser eficaz. Sin embargo, mostró que en ese momento no sería posible trabajar con ambos, ya que la aplicación de la geoarqueología requiere datos e información de nuevas investigaciones, principalmente en relación a la micromorfología de las áreas de excavación, adoptando los procedimientos utilizados y sugeridos por Babel (1975), Stein (1983), Bullock et al. (1985), Courty et al. (1989), Simpsom y Barret (1996), Goldberg y Sherwood (2006), Villagran (2010) y Barbosa (2019) y el paisaje, según Goldberg y Macphail (2006), Peña Monné et al. (2016), Sampietro-Vattuone y Peña Monné (2019).

Las fechas obtenidas por Schmitz et al. (2004) fueron calibrados utilizando el programa OxCal (Ramsey 2020) y las correlaciones establecidas en el texto utilizan la cronología indicada con las tasas de confiabilidad más altas (Tabla 1).

\section{Resultados obtenidos y discusión}

La antropización del paisaje en el municipio de Serranópolis, se evidencia por las transformaciones que ha sufrido desde las primeras ocupaciones precoloniales y, notablemente, desde la década de 1960. Esta realidad es una variable importante en el enfoque del paisaje con la investigación arqueológica. Al considerar el paisaje como un elemento cultural continuo de larga duración, en una perspectiva interactiva, este habría sido modificado por los comportamientos humanos, además de ser un agente significativo en los eventos humanos del período precolonial. En ese sentido, se considera que las áreas ocupadas habrían sido apropiadas y construidas, así como los abrigos, las fuentes de materiales y otros lugares que presenten cultura material o representaciones rupestres.

En una perspectiva más amplia, Bueno y Dias (2015) argumentan que los grupos de cazadores-recolectores ya estaban bien adaptados a paisajes holocénicos entre 12,000 y $8000 \mathrm{AP}$, en la parte oriental de América del Sur. De acuerdo con Flegenheimer et al. (2007: 22), los grupos de cazadores-recolectores que ingresaron a Sudamérica «se movían y acampaban dentro del territorio 
que conocían como propio, de manera tal que los distintos campamentos eran ocupados solo parte del año».

Como argumentó Souza (2020), para contextualizar a estos grupos humanos y comprender aspectos de sus formas de vida, es esencial discutir la ocupación del territorio utilizando la territorialidad de estos grupos. Bajo la perspectiva económica aportada por el procesualismo, el territorio puede definirse como área usualmente explotada (Higgs y Vita-Finzi 1972). Por lo tanto, como los grupos de cazadores-recolectores generalmente tienen mayor movilidad, su área de captación de recursos tiende a ser mayor. Los datos etnográficos corroboran esto, tomando como ejemplo la comunidad !Kung San, que vive en campamentos en el desierto de Kalahari y que tiene un territorio para su subsistencia, donde las actividades de caza y recolección pueden durar hasta dos semanas. Sin embargo, también tienen estrategias específicas para períodos de lluvia y sequía, que incluyen la formación de grupos con un número variable de miembros, 30 personas (seis familias) para campamentos temporales durante la temporada de lluvias y para el período de sequía, unidades con hasta cuatro grupos que se unen para diversas actividades cerca de una fuente de agua (Lee y De Vore 1976; Lee 1979; Ogot 1999). Para Anati (1988), el área de un sitio arqueológico es equivalente a la distancia máxima que un individuo puede caminar en el período de un día (50 kilómetros). Sin embargo, se debe considerar la accesibilidad del terreno, ya que ciertos factores ambientales podrían interferir con el acceso, como relieves accidentados o cursos de agua.

Estos intentos de delimitar el territorio ocupado fueron ampliamente utilizados durante el apogeo de los estudios procesualistas por Análisis Espacial, que habría surgido, según Sanjuán (2005), de las ideas de la Ecología Cultural ${ }^{7}$ durante la década de 1960, impulsando los estudios sobre el territorio y el sentido de territorialidad para los grupos humanos en tiempos pasados. Con el advenimiento del posprocesualismo, estos conceptos experimentaron cambios importantes, cuando comenzaron a considerar sus aspectos culturales y sociales (Villafañez 2012; Souza 2020). Morais (1999) considera el territorio como un elemento del paisaje dentro del cual los grupos humanos se han asentado y desarrollado sus actividades de captura, procesamiento de recursos y para otros fines no económicos. Para Criado-Boado (1999), el territorio es una construcción política que no necesariamente tiene continuidad y puede ser fragmentado. En el caso de los grupos no sedentarios, el territorio es donde estaban; es decir, cuando se movilizaban, su territorialidad se movía junto, pudiendo mezclarse con la de otros grupos (Criado-Boado 1999).

En este sentido, se entiende que la territorialidad está impregnada de «[...] estratégias que envolvem a ocupação e exploração de um determinado espaço-físico, associado à posse ou propriedade do mesmo por uma sociedade em um dado tempo» ${ }^{8}$ (Boschín 1993 en Rogge 2004: 48), involucrando tanto procesos naturales como culturales. La delimitación del territorio debe considerar la disponibilidad y la previsibilidad de los recursos fundamentales para la supervivencia, de modo que el grupo en cuestión pueda defender sus zonas fronterizas. Según Dyson-Hudson y Smith (1978 en Rogge 2004), un grupo tiene mayor movilidad y tiende a defender menos sus fronteras, cuanto más impredecibles y escasos son sus recursos.

Para el caso de Serranópolis, adoptar un concepto puramente económico no es suficiente para comprender el patrón de las ocupaciones cazadoras-recolectoras (Souza 2020). Es necesario, por lo tanto, preguntarse: ¿cuáles fueron las influencias de los agentes económicos y sociales para la delimitación del espacio geográfico?, ¿sería el río Verde, ubicado cerca de los núcleos de los sitios, un límite físico o simbólico para sus habitantes, separándolos, a lo largo del tiempo, en grupos culturales diferentes?, ¿las cascadas presentes en el área también tendrían relaciones con las prácticas culturales materializadas en el sitio?, ¿cuáles fueron las relaciones internúcleos y de estos con el paisaje?, ¿cómo fue la movilidad del grupo?, ¿su territorio sería parcialmente móvil? A partir de los estudios realizados, la región tenía de recursos naturales disponibles para los grupos de cazadores-recolectores, según lo abordado por Barbosa (1984), Schmitz y Barbosa (1985), Barbosa 
et al. (2014). Esa perspectiva aborda una territorialidad más estable y fronteras mejor definidas, en contraste con la discutida en el párrafo anterior, móvil y fluida.

Además, cuando se piensa en el territorio y la territorialidad, es esencial tener en cuenta la visibilidad, visualización e intervisibilidad de los sitios y elementos del paisaje. Para Criado-Boado (1999), la visibilidad es todo lo que se puede observar desde la ubicación del sitio, la visualización se refiere a cómo los elementos arqueológicos son vistos por las personas y la intervisibilidad es lo que se observa entre el sitio y otro elemento destacado, sea arqueológico o no. En la región de estudio es posible dibujar mapas de visibilidad e intervisibilidad para resaltar estos elementos de paisaje observables, que podrían haber sido esenciales para sus ocupantes?

Con base en estos conceptos, es posible pensar las ocupaciones en Serranópolis a partir del concepto de «lugares persistentes» que son, para Schlanger (1992: 92), «lugares habitados sucessivas vezes» ${ }^{1}$. Lo que define un lugar persistente son sus atracciones naturales y culturales, que determinarían el regreso a estos lugares específicos, creando, con el tiempo, la práctica del retorno (Thompson 2010 en Saldanha 2016). Lugares persistentes no son solo ubicaciones específicas en el paisaje, sino, lugares que permiten la creación constante de relaciones e identidades (Thompson y Moore 2012 en Saldanha 2016). Fagundes (2009) establece algunas consideraciones sobre lugares persistentes en el contexto de la arqueología brasileña.

Son, por lo tanto, lugares importantes en el territorio y para la territorialidad de los ocupantes de una región, incluso para los grupos de economía de caza, recolección y pesca con alta movilidad. Teniendo en cuenta eso, es interesante pensar, para el caso de Serranópolis, si los sitios en cuestión están en un contexto de territorialidad maleable y fluida, donde los lugares persistentes están relacionados con sitios del Complejo Arqueológico, especialmente con aquellos seleccionados como centrales. La densidad, la diversidad de la cultura material y las fechas son variables importantes en ese enfoque. En ese contexto, surgen algunas cuestiones: ¿cómo se habría establecido el sentido de pertenencia entre el grupo y su territorio? En otras palabras, ¿cómo sería la relación de este grupo con el paisaje que habitó?

Considerando la persistencia ocupacional de los sitios de la región, se entiende que la acción antrópica practicada por los grupos subsistentes de caza, recolección y pesca habría modificado el paisaje precolonial. Sin embargo, uno se pregunta: ¡en qué medida habría ocurrido esta interferencia? Esa pregunta ha guiado la búsqueda de evidencias físicas de construcción o modificación del paisaje en estas áreas, como vertederos, represamiento de canales y adaptación del espacio de la habitación, por ejemplo.

A través de la geoarqueología y de la arqueología del paisaje, no ha sido posible, hasta ahora, identificar de manera segura dichas evidencias físicas. A pesar de todo, los artefactos líticos, los restos de fauna y flora, el arte rupestre y la propia ocupación en el abrigo, entre otros, son evidencias concretas y directas de apropiación. ¡El problema está delineado! ¿Qué procedimiento metodológico puede proporcionar resultados positivos con respecto a esta intervención?, ¿la evidencia ha sido destruida, enmascarada o simplemente no identificada debido a falta de instrumentos apropiados? Rubin et al. (2015) discuten estos temas para la provincia de Goiás.

\subsection{Sitios por núcleos y aspectos principales}

Para ayudar a la caracterización y la correlación inter sitios y entre sitios y el paisaje, este texto se basó en los datos de la figura 1 , donde es posible verificar las distancias desde los sitios hasta el río Verde, siendo en promedio cuatro kilómetros. El GO-JA-13c es el más cercano (0,6 kilómetros) y el GO-JA-11a, el más alejado (9 kilómetros). Mientras que la figura 3 presenta una estimación de las áreas de los sitios, la figura 4 presenta la cantidad de objetos líticos (lascas, núcleos e instrumentos) por sitios. Todos los datos presentados se basaron en Schmitz et al. (2004). 


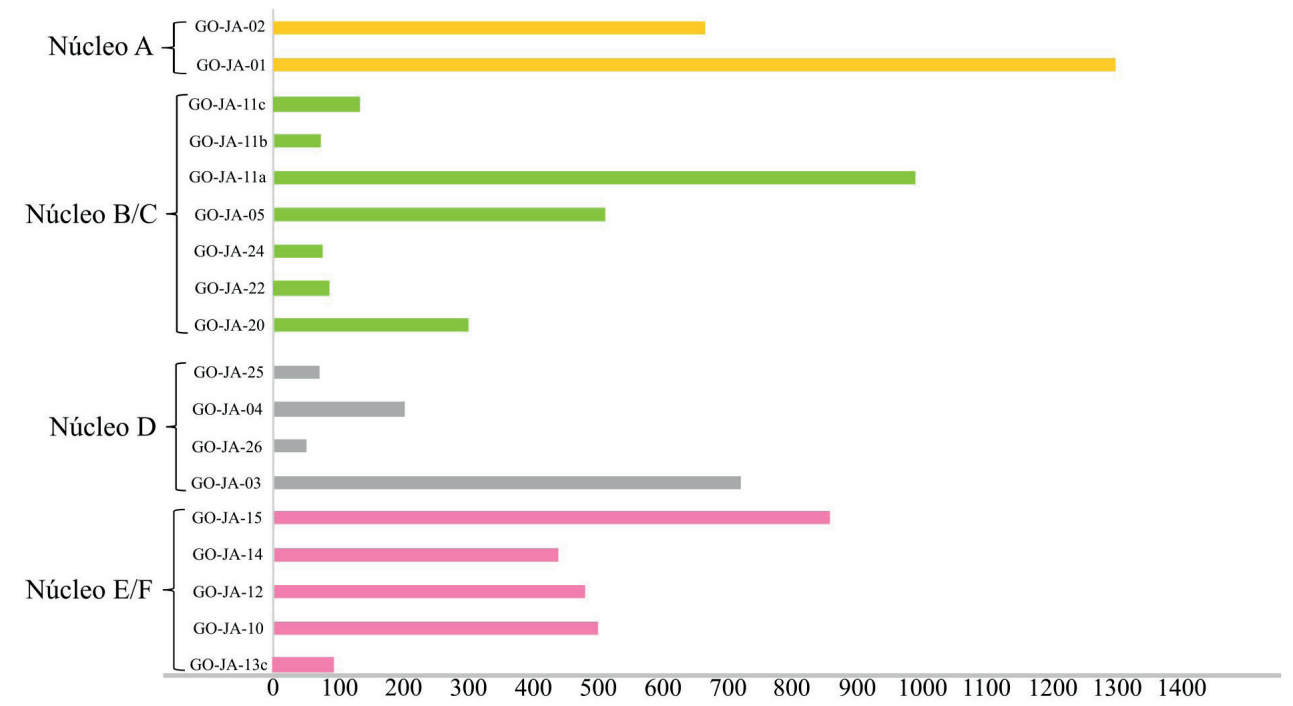

Figura 3. Estimación de áreas de los sitios por núcleos (en metros cuadrados) (fuente: Schmitz et al. 2004).

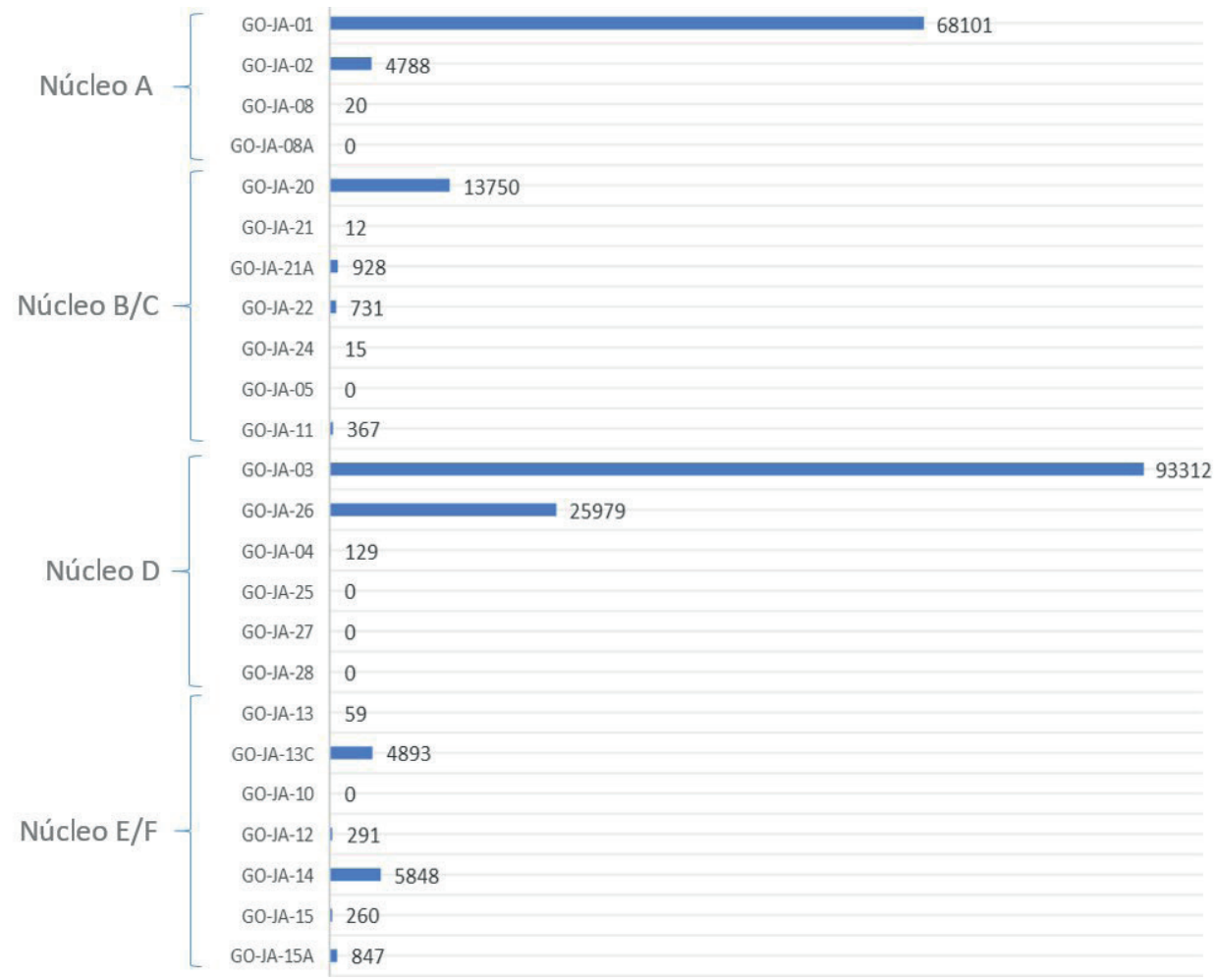

Figura 4. Análisis cuantitativo de objetos liticos por sitio y núcleo, obtenidos por muestreo (fuente: Schmitz et al. 2004). 


\subsubsection{Núcleo $A$}

El sitio GO-JA-01: presenta manifestaciones rupestres, vestigios cerámicos (fases Jataí y Tupiguarani) y líticos (fases Jataí, Serranópolis y Paranaíba), entierros humanos, huesos de fauna y restos botánicos cultivados y silvestres ${ }^{11}$. Se realizaron recolecciones en superficie, en tres pozos de sondeos y en un área de excavación de 40 metros cuadrados con fechados entre 10,580 $\pm 115 \mathrm{AP}$ (SI-3699) y $925 \pm 60$ AP (SI-3690) en el área de excavación y entre 10,400 \pm 130 AP (N-2348) y $915 \pm 75$ AP (N-2346) en un pozo de sondeo (ver Tabla 1 para correlación entre fechas no calibradas y calibradas). La figura 5 presenta el perfil sur simplificado del área de excavación, destacando cronologías y disposición de capas desde la capa $\mathrm{A}$ hasta la $\mathrm{K}$, las demás están representadas en el perfil norte. Los sitios GO-JA-01a hasta el GO-JA-01g no fueron investigados. Recientemente seis nuevos sitios han sido catalogados en las proximidades (Resende et al. 2019). El sitio GO-JA-02 tiene características tecnoculturales similares al sitio GO-JA-01, habiéndose obtenido fechados de 10,120 \pm 80 AP (SI-3108) y $9195 \pm 75$ AP (SI-3107) en un pozo de sondeo. El sitio GO-JA-08 también tiene manifestaciones rupestres, en este sitio no se hizo apertura de pozos sondeo, solo recolección superficial de material cerámico (fase Jataí), además núcleos y otros líticos que no estaban vinculados, por el momento, al contexto cronocultural establecido para la región. Cerca del sitio GO-JA-08, se identificaron bloques y afloramientos que podrían ser utilizados como fuentes de materia prima para el lascado. En el sitio GO-JA- $08 a^{12}$ solo se registraron grabados rupestres, que no fueron objeto de investigación (Schmitz et al. 2004).

Los sitios GO-JA-01 y GO-JA-02 son abrigos rocosos que ofrecen un importante espacio de circulación, lo que sin duda habría sido positivo para la ocupación humana. Ambos sitios tienen una cantidad representativa de material arqueológico, presente en la superficie hasta unos tres metros de profundidad, distribuido en capas arqueológicas que datan del Holoceno Temprano al Holoceno Tardío. De acuerdo con Schmitz et al. (2004), en los sitios hay registros de enterramientos humanos, estructuras de combustión, huesos de fauna, restos orgánicos y arte rupestre. El sitio GO-JA-01 se destaca por la presencia recurrente y abundante del material lítico en todas las capas. Su estado de conservación es bueno y se caracteriza por una diversidad de lascas (originadas en diferentes fases de las cadenas operativas de producción de instrumentos), núcleos, fragmentos de diversas materias primas e instrumentos enteros y fragmentados. Investigaciones más recientes (Lourdeau 2010; Ramos 2016; Ramos y Viana 2019; Oliveira 2019) han identificado, además de las piezas modeladas unifacialmente, un artefacto diagnóstico de la fase Paranaíba (Tradición Itaparica), diferentes esquemas de producción de instrumentos que siguen una planificación y operaciones técnicas específicas.

La cerámica presente solo en las capas superiores de los sitios GO-JA-01 y GO-JA-02 fue afiliada a la fase Jataí de la Tradición Una y a la fase Iporá de la Tradición Tupiguarani, a partir de análisis preliminares, que pueden tener cambios cuando se detallan.

$\mathrm{El}$ arte rupestre del sitio GO-JA-01 presenta una diversidad de manifestaciones gráficas, que evidencian subcategorías en tipologías; es decir, hay grupos claramente diferenciados tanto en grabados como en pinturas, además de variaciones en los colores y consecuentemente tipos de pigmentos, reflejando el dinamismo y la diferenciación de las expresiones dejadas allí. Otra evidencia de la diferencia temporal entre las expresiones es el estado de conservación de los grafismos, con algunos más evidentes y preservados, y otros más desgastados. Aunque se considere la ubicación de los grafismos en lugares más o menos expuestos a meteorización, el grado de desgaste puede indicar una mayor antigüedad. Por ejemplo, junto con expresiones muy evidentes, Resende et al. (2019) indicaron que en una cavidad de alrededor de 10 metros cuadrados se identificó un pequeño grupo de grabados, en un área afótica, que para la región es rara, si no la única, hasta ahora.

El sitio GO-JA-02 presenta pocas manifestaciones rupestres con relación al sitio GO-JA-01 con grafismos separados en diferentes grupos de expresión, así como una diversidad de pinturas no mencionadas en la investigación de Schmitz et al. (1997). En el área externa del sitio, hay dos tipos 

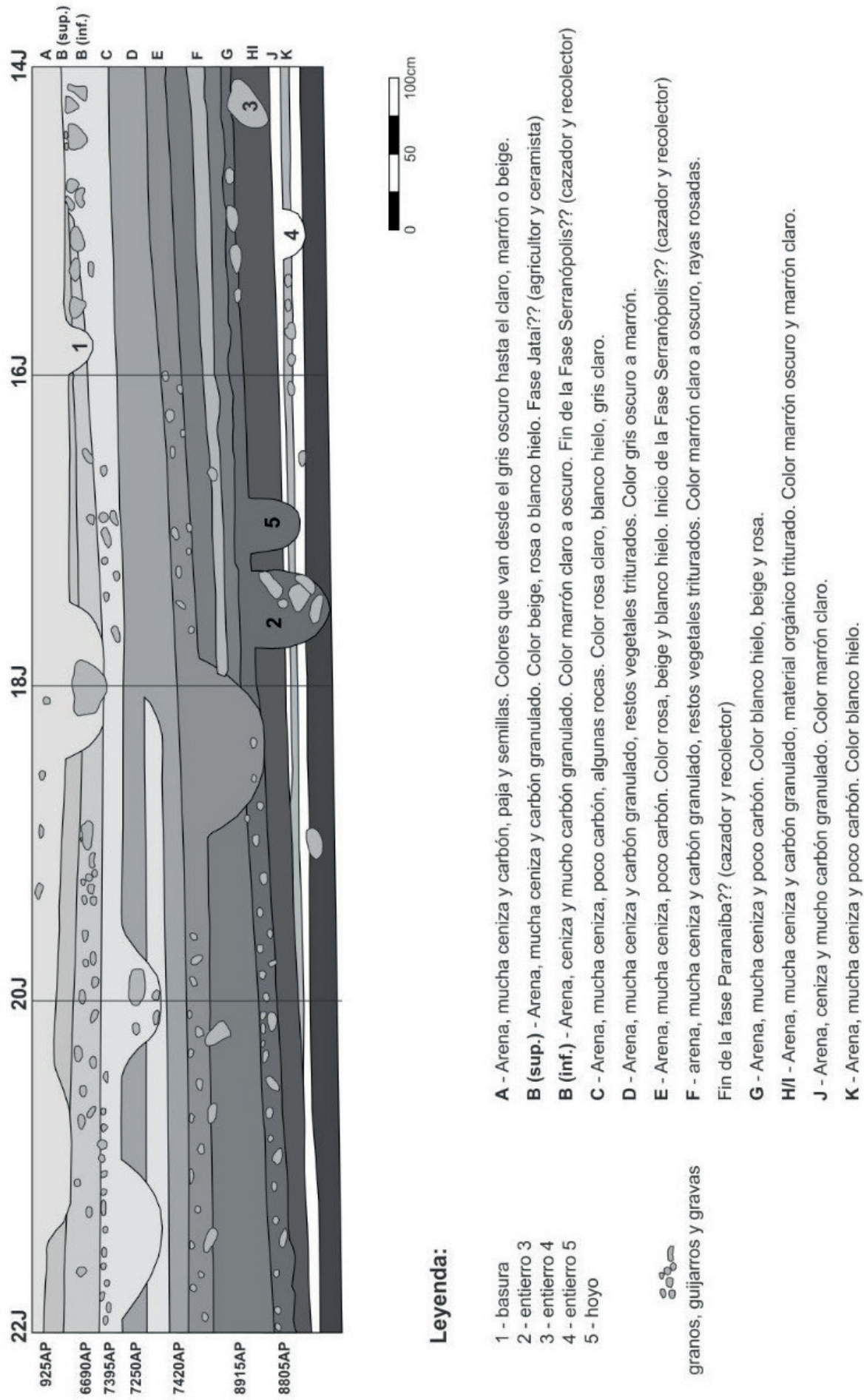

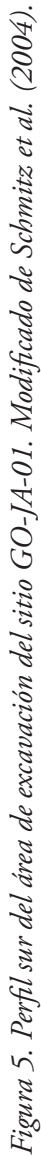


muy diferentes de pinturas, siendo uno de ellos un grupo con pigmento rojo, distribuido en varios puntos de la pared, actualmente comprometido por la meteorización, con desvanecimiento severo. También se observa un conjunto pinturas blancas (casi imperceptibles porque son pequeńas), concentradas en un nicho de soporte muy fragmentado, que se usó solo en pequeños segmentos planos de la roca (Resende et al. 2019). En el área interna del sitio, predominan los grabados, los cuales se reportan en la investigación de Schmitz et al. (1997). El sitio GO-JA-08 presenta arte rupestre, específicamente, grabados con la presencia de numerosos pies humanos en una cavidad en la parte superior derecha del afloramiento. También presenta grandes secuencias geométricas, pintura policromada y pinturas en áreas altas que ahora son inaccesibles. Los bloques y gravas que componen el piso revelan grabados y piedras de afilar.

\subsubsection{Núcleos $B / C$}

Los sitios del Núcleo B/C han sido poco estudiados por Schmitz et al. (1989, 2004), priorizando el registro y catalogación de manifestaciones rupestres, recolección de superficie y la apertura de un pozo de sondeo. El sitio GO-JA-20 presenta formaciones rupestres, enterramientos, restos cerámicos de las fases Jataí, Tradición Una y líticos de las fases Jataí, Serranópolis y Paranaíba. En este sitio se abrió un pozo de sondeo. El sitio GO-JA-21 presenta solo vestigios líticos en la superficie, no vinculados a un contexto cronocultural específico. GO-JA-21a presenta solo material lítico en la superficie, el cual no ha sido vinculado a un contexto cronocultural específico. No hubo apertura de pozo de sondeo. GO-JA-22 presenta material lítico (fases Jataí, Serranópolis y Paranaíba), cerámico (fase Jataí) y restos faunísticos, recogidos de un pozo de sondeo. El sitio GO-JA-24 presenta pinturas y grabados rupestres, fragmentos cerámicos (fases Jataí y Tupiguarani) y objetos líticos, no vinculados al contexto cronocultural establecido para la región. Los materiales se obtuvieron de un pozo de sondeo.

Entre los sitios del Núcleo C, el GO-JA-05 presenta grabados rupestres, material lítico y cerámico (fase Jataí) recogidos de la superficie y no cuantificados. GO-JA-11/1 presenta cerámica de las fases Jataí (Tradición Una) y Iporá (Tradición Tupiguarani), líticos de las fases Jataí, Serranópolis y Paranaíba, obtenidos de recolección superficial y de un pozo de sondeo. El sitio GO-JA-11/2 presenta pinturas rupestres, lascas líticas y cerámica (fase Jataí), obtenidas a través de recolección de superficie. GO-JA-11/3, presenta cerámica de la fase Jataí y lascas líticas de los niveles iniciales del pozo de sondeo (Schmitz et al. 1989, 2004).

Las manifestaciones rupestres son pocas, pero son complejas en formas. Uno de los sitios, GO-JA-11/2, ubicado en la parte superior de un afloramiento, solo tiene una pintura policroma evidente, fuera del área protegida principal. Junto a esto, en la parte baja del afloramiento, hay evidencia de muchas manchas de pigmento, posiblemente de pinturas antiguas. Por otro lado, el sitio GO-JA-05 (conocido localmente como Gruta do Mel), está completamente cubierto por grabados, con énfasis en la expresión de orificios en forma de cúpula (Bednarik 2008) y un gran grabado en un área alta que actualmente es inaccesible. Llama la atención la variedad de expresiones registradas (Schmitz et al. 1997; Resende et al. 2019).

\subsubsection{Núcleo D}

En este núcleo, el sitio GO-JA-03 presenta muchas manifestaciones rupestres, entierros humanos, restos botánicos (maíz, algodón, frutas, cuerdas y hojas), huesos de animales, estructura de combustión, restos cerámicos (fases Jataí e Iporá) y líticos (fases Jataí, Serranópolis y Paranaíba), procedentes de recolección de superficie y de siete pozos de sondeos. En el sitio GO-JA-03a se hicieron dos pozos de sondeo, registrando líticos de las fases Paranaíba y Serranópolis y cerámica de las fases Jatai y Tradição Tupiguarani. El sitio GO-JA-04 presenta pocas pinturas y grabados rupestres, además de fragmentos cerámicos de las fases Jataí y Iporá; líticos asociados a las fases Jataí, Iporá, Serranópolis y Paranaíba, resultantes de recolecciones superficiales y de pozos de sondeos. 
Se identificaron cuatro sitios más cerca del sitio GO-JA-04, los cuales se registraron como sitios GO-JA-04a a GO-JA-04d (Resende et al. 2019). El sitio GO-JA-25 solo presenta arte rupestre, aunque se realizó un pozo de sondeo. GO-JA-26 presenta pinturas rupestres, fragmentos de cerámica de las fases Jataí y líticos asociados con las fases Jataí, Serranópolis y Paranaíba, resultantes de pozos de sondeo. El sitio GO-JA-27 tiene grafismos rupestres y objetos líticos no cuantificados y no vinculados al contexto cronocultural del área. GO-JA-28 presenta pinturas rupestres y objetos líticos que tampoco están cuantificados o vinculados al contexto cronocultural del área. No fueron investigados los sitios GO-JA-03b, GO-JA-23, GO-JA-29 y uno sin nombre.

Como se puede ver en la figura 1 , los sitios en este núcleo arqueológico se distribuyen de la siguiente manera: el sitio GO-JA-03 se presenta aislado en un afloramiento rocoso y en sus alrededores hay dos afloramientos más pequeños que fueron catalogados como sitios GO-JA-26 y GO-JA-26a a una distancia de 400 y 450 metros, respectivamente. El sitio GO-JA-04 está ubicado en una pared rocosa grande y el sitio GO-JA-25 en un bloque a 30 metros, que eventualmente puede complementar al sitio GO-JA-03. Los sitios GO-JA-27 y GO-JA-28 integran otro grupo lejano, a aproximadamente 600 metros del GO-JA-03. De acuerdo con Resende et al. (2019) estos sitios integran otro conjunto de bloques cercanos entre sí, cuyos sitios principales están un poco distantes y no se localizaron en la investigación coordinada por Schmitz entre las décadas de 1970 y 1990, pero están en la fase de catalogación y registro.

En los sitios GO-JA-03 y GO-JA-26, los objetos arqueológicos son bastante representativos, sus características tecno-morfológicas, asociadas a las fechas, llevaron a Schmitz et al. (1989, 2004) a clasificarlos en los tres horizontes crono-culturales que pertenecen al Holoceno Temprano, con la tradición Itaparica; Holoceno Medio, con la fase Serranópolis y Holoceno Tardío, con la fase Jataí. Estos sitios presentan todas las fases de las cadenas operativas de producción de herramientas; sin embargo, investigaciones recientes (Fonseca 2019; Rodet et al. 2019), realizadas con materiales líticos de las capas más antiguas, apuntan al pequeño número de núcleos y una gran cantidad de lascas de modelado y fabricación de instrumentos de bordes afilados, incluida la producción no solo de planos convexos, sino también puntas de proyectiles en el sitio GO-JA-26, el cual presentó fechados de $8370 \pm 75 \mathrm{AP}$ (SI-5562) y $8880 \pm 90 \mathrm{AP}$ (SI-5563) para la capa 6. La notable cantidad de los objetos líticos del sitio GO-JA-03, que tiene fechados de $9765 \pm 75$ AP (SI-3110) para la capa 10 y $5720 \pm 50$ AP (SI-3109) para la capa 7 (Tabla 1), está relacionada con la ocupación más antigua (Tradición Itaparica), presentando un claro desequilibrio en relación con los otros sitios en la región (Fig. 4). Con respecto a la gran cantidad-de material lítico, es importante tener en cuenta que no se puede aplicar directamente al número de personas que ocupan el área. Se debe considerar otras posibilidades basadas en la oposición de las clases líticas, para inferir posibles vínculos tecnológicos y, a partir de ahí, pensar en el papel de este sitio en relación con los demás.

Con base en Schmitz et al. (1997) y Resende et al. (2019) las manifestaciones rupestres del GO-JA-03 presentan una profusión de pinturas y grabados, representados en diferentes tipos de técnicas, incluida la policromía, el grabado por escarificación y la perforación de la roca. También presenta una tipología de grabados posiblemente más antigua, impresas en rocas del piso y en un bloque dentro del abrigo, que es casi imperceptible debido a la meteorización. Tiene un piso superior con pinturas en las paredes, material lítico todavía in situ y una cavidad interna afótica (Batcave) que podría dar acceso al piso superior. El área alrededor del sitio tiene muchos bloques. A aproximadamente 400 metros de distancia del sitio GO-JA-03, parece integrar el mismo sistema, con pinturas que registran imágenes de animales.

El sitio GO-JA-04 también tiene una cavidad afótica con sedimento que se puede excavar. Debido a las características del paisaje alrededor del afloramiento, el área cercana a este sitio puede haber sido un área de caza importante en tiempos pasados, ya que se identificaron otros sitios en el área, en una secuencia de caminos entre bloques, formando laberintos y patios abiertos con diversos accesos, que pueden indicar un posible lugar donde los animales pueden quedar atrapados 
para el sacrificio. Las huellas de animales grabados en numerosos puntos de paredes friables o silicificadas, nos hacen plantear esta hipótesis; sin embargo, se deben desarrollar excavaciones y análisis más detallados.

El sitio GO-JA-25 presenta pinturas rupestres en un lado del bloque, con una representación prominente de un cardumen (Schmitz et al. 1997). En su parte posterior, una tipología diferente de punción, posiblemente representando una grande serpiente (Resende et al. 2019). Es posible que este sitio esté relacionado al sitio GO-JA-04, con una separación aproximada de 30 metros. Cerca al sitio GO-JA-27, a 30 metros de distancia, se encuentra el sitio GO-JA-28, donde hay núcleos lascados, lascas e instrumentos alrededor, incluso en el camino entre ellos. GO-JA-27 y GO-JA-28 pueden asociarse con los demás sitios. El sitio GO-JA-27, se configura, quizás, como un área de observación y representación, debido a su ubicación en la porción media/alta de un afloramiento, y a que es un pequeño abrigo rocoso, que no acomodaría más de cinco personas. Este sitio tiene líneas grabadas y pinturas en el techo; en la parte superior del afloramiento hay un gran sitio lítico.

\subsubsection{Núcleos E/F}

El Núcleo E consta de dos sitios registrados: GO-JA-13 (Véu do Muquém), que presenta pinturas y grabados rupestres y en el cual se realizó una recolección de superficie; y el sitio GO-JA-13c, que presenta pinturas, enterramientos humanos, estructuras de hogueras, objetos líticos asociados con las fases Jataí, Serranópolis y Paranaíba, restos de moluscos, cáscaras de huevo y vegetales, así como fragmentos de huesos de fauna. Los materiales arqueológicos provienen de un pozo de sondeo. Schmitz et al. (2004) mencionan que se identificaron otros 15 sitios, los cuales no han sido registrados. Recientemente, Resende et al. (2019) han identificado otros nueve sitios, designados desde GO-JA-13a hasta GO-JA-13j. Puede que estos sean parte de los mencionados por Schmitz et al. $(1998,2004)$.

El Núcleo F comprende cuatro sitios registrados. GO-JA-10 tiene presencia de grabados rupestres. En los pozos de sondeo no se identificaron materiales arqueológicos. GO-JA-12 presenta manifestaciones rupestres, estructura de combustión, fragmentos de conchas de moluscos y objetos líticos sin una correlación segura con las fases Jataí o Serranópolis, todo esto a partir de un pozo de sondeo. GO-JA-14 tiene pinturas rupestres y grabados, con un fechado de 10,740 \pm 85 AP (SI-3111) para la capa 12. Los objetos líticos, huesos de fauna y enterramientos humanos, provienen de la recolección de superficie y de dos pozos de sondeos. El sitio GO-JA-15 presenta grabados y pinturas rupestres. Se llevó a cabo la recolección de superficie y del pozo de sondeo, donde se recolectaron fragmentos cerámicos, afiliados a la fase Jataí y objetos líticos sin relación segura con la fase Jataí o la fase Serranópolis. GO-JA-15a tiene presencia de objetos líticos recogidos en la superficie, sin una relación segura con las fases Jataí o la Serranópolis. Resende et al. (2019) identificó otros cuatro sitios en los alrededores, aún no registrados.

Las representaciones rupestres muestran muy bien una abundancia de recursos debido al hecho de que aparentemente se representan patas de animales talladas en la roca y pinturas. El Núcleo 7 es el más cercano al río Verde. En el área intermedia entre los Núcleos E y F, se identificaron seis nuevos sitios en proceso de catalogación (Resende et al. 2019).

Teniendo en cuenta los fechados obtenidos en los núcleos para los grupos de cazadoresrecolectores, la variación es entre 10,740 \pm 85 AP del sitio GO-JA-14, fase Paranaíba (tradición Itaparica) de cazadores-recolectores generalizados y $5720 \pm 50$ AP del sitio GO-JA-03, de la tradición Serranópolis, para cual hay un registro intenso de conchas de moluscos que indican que están relacionadas con prácticas alimenticias, los cuales actualmente se pueden obtener cerca del río Verde. El rango de ocupación es de aproximadamente 5000 años a partir de fechas no calibradas (Schmitz et al. 1989, 2004) o de 6000 ańos en base a fechas calibradas, considerando aquellas con mayor porcentual de confiabilidad (Tabla 1 ). 
Sin embargo, es importante mencionar que no hay ninguna evidencia presente en el arte rupestre sobre la abundancia de moluscos. Siendo una importante fuente de alimentos, ¿̨no estarían presentes en las representaciones rupestres? ¿̨o su representación aún no ha sido percibida? También se destaca en los abrigos la presencia de orificios en forma de cúpulas, dispuestas en secuencias que determinan pies humanos, aislados o en secuencias grandes, rectas, circulares o semicirculares.

A pesar de la vaguedad en términos como considerable y pequeño grupo, utilizados por Schmitz et al. (1989, 2004), las evidencias indican que el paisaje fue apropiado y construido por grupos humanos que produjeron una cultura material diversa y cuantitativamente densa en algunos lugares, especialmente, con respecto a los instrumentos líticos y la representación del arte rupestre. Sin embargo, también hay evidencia de otras actividades además de la producción de instrumentos y la representación rupestre. También se habrían llevado a cabo otras actividades caracterizadas por enterramientos humanos. Todo apunta a actividades de caza, recolección de frutas, vegetales y moluscos, además de la preparación de alimentos. Estas prácticas sociales fueron realizadas durante un largo período en muchos de los sitios de la región, desde el más grande, como el sitio GO-JA01 , ubicado en el extremo noroeste del mapa en la figura 1 , hasta los pequeńos abrigos, como el GO- JA-12 (Núcleo F) y GO-JA-13 (Núcleo E), ubicados cerca a la extremidad sureste del mapa antes mencionado.

Los Núcleos C y D presentan unidades de relieve residual de arenisca con diámetros variables y un sistema de fracturas que favoreció su segmentación, dejando algunas aberturas en las fracturas. Esto facilitó la separación de bloques que permanecen cerca, algunos con pinturas y/o grabados. Algunas aberturas resultantes de fracturas, o proximidades entre bloques caídos, se volvieron adecuadas para su uso como lugar para conducir, matar o atrapar la caza, especialmente cerca de los sitios GO-JA-05 (Núcleo C) y los sitios GO-JA-03, GO-JA-04, GO-JA-25, GO-JA-26 y GO-JA-26a (Núcleo D).

Otras variables a considerar son los recursos hídricos, entre los cuales se destaca el río Verde, además de los arroyos de primer a tercer orden. No existe una variación significativa en relación con la densidad de drenaje entre los núcleos. De esta manera, el río Verde podría ser analizado como una posible barrera entre una y otra orilla. Sin embargo, como se mencionó anteriormente, la cultura material no respalda esta perspectiva. Aun así, se puede presentar una barrera temporal en períodos de lluvia intensa o como resultado de alteraciones en el curso.

El río Verde tiene un índice de sinuosidad compatible con un canal meándrico que presenta una intensa migración del canal a la llanura aluvial y, en consecuencia, puede ocurrir la variación de la posición del canal en relación a los sitios. Cerca de los seis núcleos y entre los Núcleos A y B se destacan algunos lagos formados en meandros abandonados. Esta situación también puede haber resultado en la alternancia de segmentos de canales rectilíneos y meándricos. En este contexto, la relación entre los cazadores-recolectores que ocuparon la región y el paisaje pudo haber sido influenciada por la dinámica fluvial. Cabe señalar que el río Verde pudo haber sido un lugar importante para la obtención de materia prima para la producción de instrumentos líticos, especialmente, en las graveras. Desafortunadamente, hasta la fecha, no hay investigaciones en paleo hidrología con datos relacionados con la variación del nivel base y el flujo. Se pueden establecer generalizaciones con las variaciones de lluvia en el bioma del Cerrado y con los momentos más húmedos y secos del Holoceno. También debe tenerse en cuenta que algunas cronologías calibradas se posicionan al final del Pleistoceno, lo que amplía el enfoque temporal.

La geología, directamente vinculada a las fuentes de materia prima, es similar en todos los núcleos, con arenisca silicificada (de calidad diferenciada para el lascamiento, pero omnipresente en toda el área), basalto y diabasa, así como sílex y calcedonia en guijarros y gravas también están presentes. 


\subsection{Las ocupaciones, los objetos líticos y las representaciones rupestres}

Las informaciones presentadas sobre las características de los abrigos, en relación con las condiciones de vivienda, así como los objetos líticos y las representaciones rupestres respaldan las discusiones e hipótesis de este artículo. Considerando los Núcleos A y E/F como lugares de ocupación prolongada y los otros como lugares de ocupación temporal, se establecen algunas correlaciones con las representaciones rupestres. En la investigación de Schmitz et al. (1997), la nomenclatura utilizada en el arte rupestre considera pinturas y figuras como sinónimos de expresiones hechas con: a) pigmentos, b) técnicas aditivas sobre soporte y grabados, c) petroglifos para incisiones en soportes, d) técnicas extractivas.

Con respecto a las representaciones rupestres, Schmitz et al. (1997) mencionan que en el Núcleo A se registraron 100 pinturas y 197 grabados en el sitio GO-JA-01; 125 grabados en el sitio GO-JA-08 y una pintura y 221 grabados en el sitio GO-JA-02. En el Núcleo B, según Schmitz et al. (1989, 2004), el sitio GO-JA-20 presenta cuatro pinturas y el sitio GO-JA-22, tres pinturas. Para el sitio GO-JA-24, mencionan la presencia de un «conjunto de pinturas» (Schmitz et al. 1997: 39), además de los grabados, pero no las cuantifican. Con respecto al Núcleo C, se mencionan 392 grabados en los sitios GO-JA-05 y una sola pintura en el GO-JA- $11^{13}$.

En el Núcleo D, se registraron 612 pinturas y 47 grabados en el sitio GO-JA-03; 41 figuras y 182 grabados en el sitio GO-JA-04; 14 pinturas en el sitio GO-JA-25; 22 pinturas en el sitio GO-JA-26; 151 grabados en el sitio GO-JA-27 y 15 pinturas en el sitio GO-JA-28. En el Núcleo E, había 234 pinturas y 479 grabados en el sitio GO-JA-13 y solo se mencionan los registros de arte rupestre en el sitio GO-JA-13c. Para el Núcleo F, 115 grabados en el sitio GO-JA-10; 55 grabados y siete pinturas en el sitio GO-JA-12; 101 pinturas y 748 grabados en el sitio GO-JA-14, y 21 pinturas y 1298 grabados en el sitio GO-JA-15 (Schmitz et al. 1997).

En la investigación reciente coordinada por Resende et al. (2019), para una mejor comprensión de la información heredada, se adoptó el término "grafismo» para todo el conjunto de signos rupestres, sean pinturas o grabados. Para la técnica utilizada en los grafismos se utilizan los términos petroglifos (cuando hubo incisiones en el soporte, que constituyen técnicas de extracción), o pictoglifos (cuando se aplicó pigmento en el soporte, que constituyen técnicas aditivas).

En la investigación de Resende et al. (2019) se encontraron nuevos petroglifos en el sitio GO-JA-03, de un tipo diferente. En el bloque que constituye el sitio GO-JA-25, se registró una tipología diferenciada de perforación, al lado opuesto del bloque. Nuevos petroglifos que puede haber sido hecho inicialmente con la función de moler granos (piedra tacita) fueron también observados en las gravas del piso del GO-JA-01; en el piso del área afótica parcial del GO-JA-02; en las gravas del piso del GO-JA-08; en el piso central del GO-JA-04; y en el piso del GO-JA-27. También se identificaron nuevas pinturas (pictoglifos) que no se habían registrado en los sitios GO-JA-01, GO-JA-02, GO-JA-08 y GO-JA-26.

Con respecto a las dimensiones de los sitios de Serranópolis, en la figura 3 se puede observar que en los Núcleos A, C, D y F se encuentran sitios de grandes dimensiones, con más de 700 metros cuadrados. Schmitz et al. (2004) habían sugerido que los sitios más pequeños, de alrededor de 100 metros cuadrados, estarían vinculados a los más grandes. Existe un consenso al respecto; sin embargo, aún es necesario comprender la naturaleza de las relaciones entre tales unidades, así como también sobre la cantidad de personas que habrían ocupado las áreas abrigadas de los sitios.

Un aspecto a tener en cuenta en estos temas es la falta de fechas en muchos sitios, especialmente en aquellos con dimensiones más pequeñas. Cabe agregar que los objetos líticos son los elementos más constantes entre todos los núcleos, pero todavía faltan análisis y comparaciones entre las tecnologías líticas y los diferentes tipos de sitios. Actualmente, se están llevando a cabo iniciativas para contrarrestar esta deficiencia, pero aún no es suficiente, ya que algunas excavaciones realizadas tienen problemas con contextos estratigráficos, que no son siempre claros. Entre los temas que aún deben investigarse también se destaca la percepción ocupacional del área, que sería relevante 
analizar desde un aspecto más amplio, no limitado al área del abrigo rocoso, sino también considerando su entorno, o cuenca de contribución, teniendo en cuenta los diversos recursos que podrían oponerse a posibles situaciones adversas a la protección del grupo. Además, las investigaciones realizadas inicialmente y las más actuales no tienen fechas para las pinturas rupestres, lo que dificulta su inserción en el contexto temporal de los vestigios arqueológicos.

Las figuras 3 y 4 permiten análisis que involucran las áreas de los sitios, los núcleos y la cantidad de materiales líticos. Por ejemplo, el sitio GO-JA-03, con un área aproximada de 700 metros cuadrados, es el que tiene la mayor cantidad de objetos líticos (más de 90,000 obtenidos en siete pozos de sondeos con un área total de 27.5 metros cuadrados). Por su parte, el sitio GO-JA-01, con aproximadamente 1300 metros cuadrados, presenta alrededor de 68,000 objetos líticos solo en el área de excavación de 40 metros cuadrados, y parece «ter sido cômodo até para acampamentos permanentes de um grande grupo» ${ }^{14}$ (Schmitz et al. 1989: 34).

$\mathrm{Al}$ igual que en relación con los líticos, también hay una diferencia cuantitativamente significativa con respecto a la distribución de las representaciones rupestres. Se tienen 4145 (1071 pinturas y 3074 grabados) en la margen derecha (Núcleos D, E y F) y 1058 (123 pinturas y 935 grabados) en la margen izquierda (Núcleos A, B y C) del río Verde. En base en esta observación, cabe la pregunta: ¿estará esta diferencia condicionada por la intensidad de la ocupación?, ¿o se trata de diferentes núcleos ocupados en diferentes momentos?, ¿hubo áreas preferenciales para las representaciones? Como se mencionó, esta diferencia también puede estar relacionada con el registro realizado por la primera investigación. En este sentido, ¿̇sería posible pensar en problemas inherentes a los procedimientos metodológicos de la investigación? Es importante hacer estas preguntas, pero aún no es posible responderlas.

\subsection{Las ocupaciones, el paisaje, territorio y territorialidad}

El intervalo de tiempo en el que la ocupación del sitio GO-JA-01 (Núcleo A) ocurrió por los grupos no sedentarios discutidos en el artículo, aproximadamente, se registró con base en la cronología de $6690 \pm 90$ AP de la capa B inferior y 10,580 \pm 115 AP de la capa Q del área de excavación (Tabla 1). Desafortunadamente, no hay como correlacionar con el Núcleo $F$, ya que para ese núcleo solo se obtuvo una datación de 10,740 \pm 85 AP (SI-3111) para la capa 12 del pozo de sondeo I/II del sitio GO-JA-14. La temporalidad de la ocupación refuerza el sentido de persistencia ocupacional y también la capacidad del área para la subsistencia de grupos humanos.

Criado-Boado (2012: 323) presenta en la figura 53 de su trabajo el «dispositivo interpretativo para el estudio de las formaciones socioculturales prehistóricas», donde clasifica los grupos de cazadores y cazadores-recolectores con una acción pasiva en relación a la racionalidad económicoambiental y con racionalidad cazadora en cuanto al padrón de racionalidad. El enfoque adoptado por Schmitz y Barbosa (1985) y Barbosa (2002) también sigue esta perspectiva, considerando que los grupos de cazadores-recolectores en Serranópolis se adaptaron al bioma Cerrado, presentando un modelo de subsistencia basado en los recursos naturales del bioma. Por otro lado, Rubin et al. (2015) establecen consideraciones respecto a la adaptación y manejo de los recursos naturales por grupos precoloniales en la provincia de Goiás, considerando que ambos podrían modificar el paisaje.

La perspectiva adoptada aquí, es que tanto la adaptación como el manejo afectan el paisaje, incluso para grupos que subsisten en la caza, la recolección y la pesca, en oposición al término pasivo utilizado por Criado-Boado (1999). Sin embargo, para abordar la relación de los grupos con el paisaje, es importante considerar aspectos como: a) tamańo del grupo, b) tipos de desplazamiento, c) tiempo de permanencia, d) reocupación concomitante de una misma área por diferentes grupos y, principalmente, e) la forma de interactuar con el paisaje — tanto para utilizar los recursos naturales disponibles, cuanto para otros fines no económicos-. 
La apropiación y la construcción del paisaje también involucran temas como la subsistencia y el sistema de subsistencia, tema abordado por Bonomo et al. (2019), utilizando perspectivas de diferentes autores. El sistema de subsistencia de los grupos cazadores-recolectores o alfareros está relacionado con la movilidad, con el territorio y con los recursos naturales y, en consecuencia, con las formas de apropiación y construcción del paisaje.

Un caso de estudio que sirve como contraste a la realidad de Serranópolis, en relación con la intencionalidad de ocupar un área, es presentado por Martínez (1999), quien analiza el transporte y la concentración de rocas de cuarcita utilizadas en la producción de herramientas e instrumentos por los cazadores-recolectores en el Holoceno Temprano en la región del curso medio del río Quequén Grande, Argentina. Esta actividad compensó la ausencia de materia prima en ciertas áreas; es decir, una acción intencional dirigida a minimizar la ausencia de un recurso importante, que resultó en la apropiación y construcción del paisaje o paisajes. Una vez que los grupos de cazadores-recolectores se movieron, establecieron senderos, cacerías organizadas, exploraron y seleccionaron materias primas rocosas y vegetales, produjeron instrumentos en diferentes ambientes, hicieron hogueras (que implica obtener madera y ocupar los alrededores), etc. Las actividades de recolección y de caza, por ejemplo, impactaron o alteraron el paisaje. En el caso de la caza, independientemente de la modalidad, de acuerdo con aquellas propuestas por Churchill (1993: 11-13), "handicap hunting, ambush hunting, hunting by approach, hunting for persecution e hunting by encountern ${ }^{15}$, dejaron marcas, aunque sutiles, en el paisaje.

Por lo tanto, en base a lo que se conoce actualmente, los senderos resultantes del desplazamiento de humanos para diferentes propósitos, fueron y son lugares donde el flujo de agua de lluvia puede originar pequeńos procesos erosivos, como surcos o canales y, dependiendo del tipo de suelo, cárcavas ${ }^{16}$. Las áreas de lascamientos, como las graveras asociadas con los cauces de los ríos o cerca de las orillas, o incluso retirar rocas y/o la remoción de la vegetación y el suelo para remover gravas y bloques, también cambió el paisaje o dejaron marcas en este. Las actividades de caza también pueden implicar la caída o remoción y quema de vegetación y el movimiento o la alteración del suelo, sea por desplazamiento de humanos o de animales. Una asociación de estas actividades también podría conducir a la formación de procesos erosivos, como se mencionó anteriormente. Finalmente, se considera que los campamentos y abrigos con la cultura material y nuevos elementos orgánicos e inorgánicos, por ejemplo, han alterado las características naturales de suelos y sedimentos.

Anteriormente se enumeraron algunas actividades que pueden ser asociadas con grupos de cazadores-recolectores que vivieron en la región de Serranópolis. Analizándolas, se propone que además de dejar marcas, fueron los primeros a producir depósitos tecnogénicos (DT). Oliveira $(1990,1994)^{17}$ propuso la clasificación de DT originados por la acción de humanos en: a) construidos (consecuencia de la acción antrópica intencional), b) inducidos (en los cuales la acción antrópica cambia los depósitos naturales) y c) modificados (cuando los elementos/componentes de origen antrópico alteran el suelo o incluso los depósitos naturales). Como lo menciona Peloggia (2017), estos depósitos representan la apropiación y construcción del paisaje. Hay otras clasificaciones de DT, como las de Fanning y Fanning (1989) y Peloggia et al. (2014). Teniendo en cuenta las actividades mencionadas, los DT inducidos y modificados se produjeron en una relación de causa (intencional)-consecuencia (no intencional) en los suelos, sedimentos o en la colmatación de los arroyos (Rubin et al. 2019).

Flegenheimer et al. (2007: 23) establecen algunas características de grupos de cazadores- recolectores, abordando cuestiones como la movilidad y la explotación de los recursos naturales. Schaan (2009: 9) menciona las transformaciones en el paisaje amazónico por parte de grupos de cazadoresrecolectores y agricultores a través del manejo de especies vegetales. Neves (2006: 24) sostiene que los primeros grupos humanos que ocuparon la región amazónica, basados en la caza, la recolección y la pesca, tenían una «estratégia de exploração de recursos que valorizava a biodiversidade caracterís- 
tica da regiāo» ${ }^{18}$. El bioma Cerrado mantuvo contacto con otros biomas brasileños, con excepción de la Pampa, y la mención de la región amazónica, por ejemplo, se justifica por la movilidad de los grupos precoloniales. En la perspectiva adoptada aquí, cuestiones como el patrón de subsistencia de los grupos humanos y los cambios en el paisaje permiten una serie de discusiones, una de las cuales es la producción de depósitos antropogénicos (tecnogênicos), ya mencionados.

El análisis y la correlación de las variables discutidas en este artículo, además de las características ya establecidas para los grupos de cazadores-recolectores, asocian a estos grupos como los precursores de los DT en la región de Serranópolis.

En el área del Complejo Arqueológico de Serranópolis se produjeron desplazamientos de grupos precoloniales y, si en los abrigos las ocupaciones están bien representadas con la cultura material y las representaciones rupestres, por ejemplo, a cielo abierto la realidad es otra. No obstante, entre los sitios las evidencias de esa ocupación pueden haber sido destruidas o enmascaradas por procesos naturales y acciones antrópicas, como se discute al inicio del artículo. En el caso del área entre los Núcleos A y E/F, por ejemplo, los neosuelos cuarzarenicos y la eliminación de la cubierta vegetal de Cerrado, pueden haber afectado o favorecido la destrucción de estas evidencias. Sin embargo, Serranópolis es una de las pocas áreas en la Meseta Central brasileña donde hay un conjunto de sitios arqueológicos bien conservados que permite establecer consideraciones y discusiones con el paisaje.

El tiempo transcurrido después de las ocupaciones de los cazadores-recolectores y la antropización es el principal obstáculo, ya que se reducen las pruebas o las posibilidades de investigación. Teniendo en cuenta este problema, se sugiere que se desarrolle un programa de investigación en las áreas entre los Núcleos A y F delimitados por Schmitz et al. (1989, 2004). Esto no significa que las otras áreas no tengan potencial arqueológico, por el contrario, es solo una opción debido a las evidencias ya conocidas, las consideraciones y las hipótesis desarrolladas en este artículo. Para Crumley (1994), la relación histórica entre los humanos y el medio ambiente puede verificarse o interpretarse en el paisaje. Se presentó y discutió en este artículo las actividades asociadas a los grupos de cazadores-recolectores con el potencial para transformar el paisaje, lo que permite repensar la intensidad de las acciones de los grupos humanos, al menos en el área definida como Complejo Arqueológico de Serranópolis.

Considerando el área definida en la figura 1, los grupos de cazadores-recolectores ocuparon y reocuparon ciertos abrigos, se movieron dentro de un territorio, se apropiaron y construyeron paisajes durante aproximadamente 5000 o 6000 ańos. Con esta movilidad dejaron algunas evidencias, las cuales hacen que el DT, en este momento, se presente como una variable de investigación. En este sentido, el área delimitada sigue siendo un contexto para ser preservado y estudiado, un testigo único aún capaz de proporcionar información sustancial sobre los grupos que lo ocuparon.

Con el objetivo de preservación, ya se han elaborado algunas iniciativas dirigidas a proteger el patrimonio arqueológico de Serranópolis, destacando los Diagnósticos para Chancela de Paisagem Cultural, solicitado por el Instituto do Patrimônio Histórico e Artístico Nacional (IPHAN) (Barbosa et al. 2009; Oliveira y Souza 2009; Martins 2010), además de Lima (2016), que presentó un plan de medidas a implementar con la participación de los gobiernos municipal, provincial y federal, así como de la comunidad. En 2019, se desarrolló el proyecto Açôes Emergenciais de Conservação da Pinturas e Gravuras Rupestres nos Sítios de Abrigos do Complexo Arqueológico de Serranópolis, solicitado por el IPHAN y ejecutado por la empresa MRS Estudos Ambientais (Resende et al. 2019). Este proyecto tuvo como objetivo trabajar con los 10 sitios que integran los Núcleos A (GO-JA-01 y GO-JA-02), Núcleo C (GO-JA-03, GO-JA-04, GO-JA-25, GO-JA26, GO-JA-27 y GO-JA-28) y Núcleo E/F (GO-JA-13 y GO-JA-13c), y resultó en acciones de conservación centradas principalmente en la limpieza de los abrigos, eliminación de los nidos de abejas africanas (lo que dificultaba que las personas se acercasen a los sitios GO-JA-01, GO-JA-03 y GO-JA-25), limpieza de la vegetación que interfería en los paneles rupestres de todos los sitios, 
limpieza de termitas e identificación de otros animales de la microfauna que cubrían las manifestaciones rupestres de los abrigos. Además, fueron hechos nuevos croquis de los sitios con mapeo de batcaves, georreferenciación y revisión de los formularios de registro de los sitios en la base de datos del Registro Nacional de Sitios Arqueológicos (CNSA)/IPHAN. El trabajo también permitió un amplio registro de imágenes que se utilizarán en la revisión del arte rupestre, imágenes de drones para estudios de paisaje y cientos de nuevas informaciones, todas relacionadas con temas de preservación y conservación como el centro de atención para la gestión adecuada de este patrimonio arqueológico y cultural.

\section{Consideraciones finales}

Los datos e información presentados en las discusiones permitieron un acercamiento al paisaje de acuerdo a los objetivos propuestos para el artículo, señalando variables con mayor y menor densidad de información. También se mostraron limitaciones en cuanto a los procedimientos utilizados, siendo necesario, por ejemplo, complementar el reconocimiento arqueológico, con excavaciones de nuevos sitios, investigar la cronología de las representaciones rupestres, los impactos de los procesos naturales y antropogénicos sobre el paisaje y los abrigos. Por otro lado, se discutió la relación de los depósitos tecnogénicos y los grupos cazadores-recolectores y el uso de la arqueología del paisaje y la geoarqueología.

Este artículo permite un flujo de informaciones que involucra los resultados de las investigaciones llevadas a cabo entre las décadas de 1970 y 1990 y entre las décadas de 2000 y 2020 . Los resultados presentados por Schmitz et al. $(1989,1997,2004)$ señalaron la necesidad de continuidad de las investigaciones. Las investigaciones recientes han traído nuevos temas académicos y científicos, así como nuevas perspectivas con respecto al paisaje en el pasado, la preservación y conservación de los sitios y la gestión del patrimonio arqueológico del Complejo de Serranópolis.

$\mathrm{Al}$ analizar toda la producción científica y técnica relacionada con la arqueología de Serranópolis, así como el potencial de investigación de la región, se percibe las varias perspectivas a abordarse y nuevos temas a desarrollarse. Con respecto a este artículo, se optó por un determinado marco temporal y cultural debido a la complejidad del área y cuestiones a explorarse. El paisaje, por ejemplo, podría abordarse de forma más directa desde perspectivas sociales o simbólicas, como propuesto por Shanks y Hodder (1995), Tilley (1994, 2014), Ingold (2000) y Pellini (2014).

Luego de casi cincuenta años de investigación, con interrupciones, Serranópolis presenta un rico contexto arqueológico en relación con la cultura material, representaciones rupestres, cronologías y estratigrafía, por ejemplo. Una investigación que se inició bajo la perspectiva histórico-culturalista fue también objeto de investigación bajo la perspectiva procesualista y más recientemente posprocesualista. Así mismo, muchas cuestiones necesitan tener continuidad, reanudadas o empezadas, en relación a la cultura material (lítica y cerámica), cronologías de las representaciones rupestres, estratigrafía, paisaje, territorio, movilidad, micromorfología, paleoambiente, patrón de subsistencia y territorialidad.

\section{Notas}

${ }^{1}$ Los neosoles tienen menos de 20 centímetros de espesor. Los neosoles cuarzoarénicos están formados predominantemente por granos de cuarzo y los litólicos por fragmentos de roca (Santos et al. 2018).

${ }^{2}$ Suelos minerales que pueden tener horizontes bien definidos. Espesor generalmente superior a 1,5 metros (Santos et al. 2018).

${ }^{3}$ El término Cerrado, originalmente llamado Sabana Tropical, se utiliza como definición de un bioma o dominio fitogeográfico de ocurrencia predominante en la meseta central brasileña, en áreas 
caracterizadas por un clima de dos estaciones, con inviernos secos y veranos lluviosos. Constituye un complejo vegetacional con relaciones ecológicas y fisonómicas con otras sabanas tropicales americanas, caracterizándose por una alta diversidad florística con más de 11,000 especies conocidas y altos índices de endemismo (Ribeiro y Walter 2008). Comprende dos estratos, uno herbáceo con predominio de hierbas y otro arbustivo a arbóreo con vegetación leńosa en diversas proporciones (Ribeiro y Walter 2008).

${ }^{4}$ Aspectos como la composición vegetal y la densidad del estrato arbóreo definen tres tipos de formaciones para el bioma: bosque, sabana y pradera. Estas formaciones comprenden un conjunto de fitofisonomías que caracterizan el mosaico vegetacional del bioma del Cerrado. El término fitofisonomía se refiere a los aspectos relacionados con la fisonomía de la vegetación, el complejo florístico y el medio ambiente. Las formaciones forestales incluyen bosques ribereños, bosques de galería, bosques secos y cerradão. Las formaciones de sabana incluyen el cerrado denso, el cerrado típico o restringido, el cerrado ralo, el cerrado rupestre y las veredas. Las formaciones de pastizales incluyen el campo sujo, el campo limpo y el campo rupestre (Ribeiro y Walter 2008).

${ }^{5}$ Tipo de fitofisonomía entre las formaciones de sabana del bioma del Cerrado, caracterizada por la presencia de la palmera buriti (Mauritia sp.), que emerge entre las especies arbustivo-herbáceas en agrupaciones de densidad variable.

${ }^{6}$ "donde los humanos vivían, trabajaban o realizaban una tarea».

${ }^{7}$ La ecología cultural fue una corriente de la antropología traída a la arqueología desde el advenimiento del procesualismo y que se ocupaba principalmente de crear métodos científicos para estudiar la relación entre los seres humanos y el entorno en que viven. Esta corriente fue fundamental para el desarrollo del Análisis Espacial (Sanjuán 2005).

${ }^{8}$ «[...] estrategias que involucran la ocupación y exploración de un determinado espacio físico, asociado con la tenencia o propiedad del mismo por una sociedad en cierto periodo de tiempo».

${ }^{9}$ Ese abordaje está siendo realizado en algunos sitios por Francisco Catalano en su tesis de doctorado.

${ }^{10}$ «Lugares habitados sucesivas veces».

${ }^{11}$ Para la relación de plantas cultivadas y vegetales naturales ver Schmitz et al. (2004).

${ }^{12}$ Este sitio, mencionado por Schmitz et al. (2004) no existe más, siendo ese lugar actualmente ocupado por pastaje en la hacienda Sem Tinta. Por otro lado, fue encontrado un afloramiento con pintura, a 250 metros del sitio GO-JA-08 (Resende et al. 2019).

${ }^{13}$ Importante apuntar que toda esa revisión del arte rupestre está en desarrollo para la tesis de doctorado de Fernanda Elisa Costa Paulino Resende, también autora en este artículo.

14 «haber sido cómodo incluso para campamentos permanentes de un gran grupo»

15 «caza de animales heridos, caza por emboscadas, caza por aproximación, caza por persecución y caza por encuentros». de lluvia.

${ }^{16}$ Concavidad resultante de la erosión del suelo, cuya principal causa es la escorrentía de agua

${ }^{17}$ Rubin et al. (2019) utilizaron la proposición de Oliveira (1990) para los DT identificados en el Centro Histórico de Salvador, Bahia.

${ }^{18}$ «estrategia de exploración de recursos que valora la biodiversidad característica de la región». 


\section{Referencias}

Almeida, F. F., C. D. Carneiro y A. Bartorelli (2012). O magmatismo pós-Paleozóico no Brasil, en: Y. Hasui, C. D. R. Carneiro, F. F. M. Almeida y A. Bartorelli (Orgs.), Geologia do Brasil, 430-452, Editorial Beca, São Paulo.

Anati, E. (1988). Origini dell'arte e della concettualitá, Jaca Book, Milán.

Andrade, J. S. (2018). Abrigo, representaçóes rupestres e impactos naturais no sítio GO-JA-02, Serranópolis, Goiás, tesis de pregrado en arqueología, Instituto Goiano de Pré-História e Antropologia, Pontifícia Universidade Católica de Goiás, Goiânia.

Araujo, M. M. (2018). Compartimentação da paisagem e recursos naturais: uma proposta para a dinâmica dos grupos pré-coloniais dos sítios GO-JA-01 e GO-JA-02, tesis de pregrado en arqueología, Instituto Goiano de Pré-História e Antropologia, Pontifícia Universidade Católica de Goiás, Goiânia.

Babel, U. (1975). Micromorphology of soil organic matter, en: J. E. Gieseking (Ed.), Soil components: organic components. I, 369-473, Springer-Verlag, Nueva York.

Barberi, M. (2001). Mudanças paleoambientais durante o Quaternário tardio em áreas de cerrados do Planalto Central: o estudo da Lagoa Bonita, tesis de doctorado em Geología, Universidade de São Paulo, São Paulo.

Barberi, M. y M. S. Lima-Ribeiro (2008). Evolução da Paisagem nas Áreas de Cerrados, en: H. Gomes (Coor.) Universo do Cerrado, 15-78, PUC Goiás, Goiânia.

Barberi, M., M. L. Salgado-Labouriau y K. Suguio (2000). Paleovegetation and paleoclimate of "Vereda de Águas Emendadas", central Brazil, Journal of South American Earth Sciences 13, 241-254.

Barbosa, A. S. (1984). O período arqueológico arcaico em Goiás, Anuário de Divulgação Científica 10, 85-97. Barbosa, A. S. (2002). Andarilhos da claridade: os primeiros habitantes do cerrado, PUC Goiás, Goiânia.

Barbosa, A. S., P. I. Schmitz, A. Teixeira Neto y H. Gomes (2014). O piar da Juriti Pepena - Narrativa ecológica da ocupação humana do cerrado, PUC-Goiás, Goiânia.

Barbosa, J. B. (2019). A aplicação da geoquímica e micromorfologia na detecção de solos antrópicos em assentamentos ceramistas Uru na bacia do Rio Araguaia, Goiás, Brasil, tesis de maestría en arqueología, Universidade de São Paulo, São Paulo.

Barbosa, M. O., J. C. R. Rubin y E. C. Castro (2009). Projeto Estudos para Chancela de paisagem cultural: diagnóstico arqueológico do aglomerado Manuel Braga - Pousada das Araras e georeferenciamento de sitios arqueológicos no município de Serranópolis, Goiás, Instituto Goiano de Pré-História e Antropologia, Pontifícia Universidade Católica de Goiás, Goiânia.

Barreto, M. V. (2010). Abordando o passado: uma introduçäo à Arqueologia, Editora Paka-Tatu, Belém.

Bartorelli, A. (2012). Contexto geológico e evolução da rede hidrográfica no Brasil, en: Y. Hasui, C.D. R. Carneiro, F. F. M. Almeida y A. Bartorelli (orgs.), Geologia do Brasil, 574-610, Editorial Beca, São Paulo.

Bednarik, R. G. (2008). Cupules, Rock Art Research Journal 25 (1), 61-100.

Bermúdez, M. (2017). Los suelos ándicos y sus efectos en el registro arqueológico, en: M. Ugalde (ed.), Estudios de Antropología y Arqueología. II, Volcanes, Cenizas y Ocupaciones Antiguas en Perspectiva Geoarqueológica, Pontificia Universidad Católica del Ecuador, Quito.

Bicho, N. F. (2011). Manual de arqueologia pré-histórica, Ediciones 70, Lisboa.

Bitencourt, A. L. (2008). Princípios, Métodos e Algumas Aplicaçôes da Geoarqueologia, en: J. C. R. de Rubin y R. T. Silva (orgs.). Geoarqueologia: teoria e prática, 41-70, PUC Goiás. Goiânia.

Bonomo, M., F. Skarbun y L. Bastourre (2019). Subsistencia y alimentación en arqueologia: una aproximación a las sociedades indígenas de América precolombina, Universidad Nacional de La Plata, La Plata.

Branton, N. (2009). Landscape Approaches in Historical Archaeology, The Archaeology of Places, en: T. Majewski and D. Gaimster (eds.), International Handbook of Historical Archaeology, 51-65, Springer, Nueva York.

Bueno, L. y A. Dias (2015). Povoamento inicial da América do Sul: contribuiçôes do contexto brasileiro, Estudos Avançados 29 (3), 119-147.

Bullock, P., N. Fedoroff, A. Jongerius, G. Stoops, T. Tursina y U. Babel. (1985). Handbook for soil thin section description. Waine Research Publications, Wolverhampton.

Campos, L. C. S. (2019). Dicionário do Patrimônio Cultural: Sítio Arqueológico. http://portal.iphan.gov.br/ dicionarioPatrimonioCultural/detalhes/91

Carvalho, J. S. (2019). Perdas de solo a montante do sítio arqueológico GO-JA-02, Serranópolis, Goiás: impactos ao patrimônio cultural, tesis de pregrado en arqueología, Instituto Goiano de Pré-História e Antropologia, Pontifícia Universidade Católica de Goiás, Goiânia.

Cashdan, E. (1983). Territoriality among human foragers: ecological models and an application to four bushman groups, Current Anthropology 24 (1), 47-66. 
Castiñeira, C., A. Blasi, G. Politis, M. Bonomo, L. del Puerto, R. Huarte, J. Carbonari, F. Mari y F. GarcíaRodríguez (2013). The origin and construction of pre-Hispanic mounds in the Upper Delta of the Paraná River (Argentina). Archaeological and Anthropological Science 5, 37-57.

Churchill, S. E. (1993). Weapon technology, prey size selection, and hunting methods in modern hunter-gatherers: implications for hunting in the Palaeolithic and Mesolithic, Archeological Papers of the American Anthropological Association 4 (1), 11-24.

Courty, M. A., P. Golberg y R. Macphail (1989). Soils and micromorphology in archaeology. Cambridge University Press, Cambridge.

Criado-Boado, F. (1999). Del terreno al espacio: planteamientos y perspectivas para la arqueología del paisaje, Capa 6, Criterios y Convenciones en Arqueología del Paisaje, 1-58, Grupo de Investigación en Arqueología de Paisaje, Universidad de Santiago de Compostela, Santiago de Compostela.

Criado-Boado, F. (2012). Arqueológicas, la razón perdida, Belaterra, Barcelona.

Crumley, C. L (ed.) (1994). Historical ecology: cultural knowledge and changing landscapes, School of American Research Press, Santa Fe.

Do Carmo, F. P., M. Barberi y J. C. Rubin de Rubin (2003). Análise palinológica de sedimentos do Quaternário Tardio, a partir de 44.000 anos AP, na regiáo centro-sul do Estado de Goiás, Brasil, Actas del IX Congreso de la Asociación Brasilera de Estudios del Cuaternario, 294, Recife.

Fagundes, M. (2009). O conceito de paisagem em Arqueologia - os lugares persistentes, Holos environment 9 (2), 301-315.

Fanning, R. J. y M. C. B. Fanning (1989). Soil: morphology, genesis and classification, J. Wiley, Nueva York.

Feder, K. L. (2009). Site survey, en: T. R. Hester, H. J. Shafer y K. L. Feder (orgs.), Field methods in Archaeology, 41-68, Left Coast Press, Walnut Ceek.

Fernandes, A. B., F. E. C. P. Resende, S. M. da Silva, U. F. Souza, J. C. R. Rubin, M. Barberi, M. E. Bichuette, T. Zepon y J. E. Galláo (e.p.). Rock-art in the Cerrado: Cultural and natural heritage conservation come together at Serranopólis, Goiás, Brazil, en: A. B. Fernandes, M. Marshall e I. Domingo Sanz (eds.), Global perspectives for the conservation and management of open-air rock art site, Routledge, Londres/Nueva York. e.p.

Flegenheimer, N., C. Bayón y A. Pupio (2007). Llegar a un nuevo mundo: la arqueología de los primeros pobladores del actual territorio argentino, Editorial Antropofagia, Buenos Aires.

Fonseca, C. R. (2019). Para além dos «planos-convexos»: análise tecnofuncional dos instrumentos líticos do holoceno antigo no sítio arqueológico GO-JA-26, Serranópolis, Goiás, tesis de pregrado en arqueología, Instituto Goiano de Pré-História e Antropologia, Pontifícia Universidade Católica de Goiás, Goiânia.

French. C. (2003). Geoarchaeology in action. Studies in soil micromorphology and landscape evolution. Routledge, Londres.

Giannini, P. C. F., X. S. Villagran, M. Fornari, D. R. Nascimento, P. M. L. Menezes, A. P. B. Tanaka, D. Assunção, P. DeBlasis y P. G. C. Amaral (2010). Interações entre evolução sedimentar e ocupação humana pré-histórica na costa centro-sul de Santa Catarina. Boletim do Museu Paraense Emílio Goeldi. Ciências Humanas 5 (1), 105-128.

Goldberg, P. y R. I. Macphail (2006). Practical and theoretical geoarchaeology. Blackwell Publishing, Oxford.

Goldberg, P. y S. Sherwood (2006). Deciphering human prehistory through the geoarchaeological study of cave sediments. Evolutionary Anthropology 15, 20-36.

Griphus Consultoria (2006). Projeto de Levantamento Arqueológico na Faixa de Servidão da Linha de Transmissão da UHE-Espora - Cachoeira Alta-GO $(103 \mathrm{Km})$, relatório final, Griphus Consultoria, Goiânia.

Griphus Consultoria (2007). Projeto de Resgate do Patrimônio Cultural e Arqueológico da AHE Espora-GO, relatório final, Griphus Consultoria, Goiânia.

Higgs, E.S. y C. Vita-Finzi (1972). Prehistoric economies: a territorial approach, en: E. S. Higgs (ed.), Paper in Economic Prehistory, 27-36, University Press, Cambridge.

Holliday, V. T. (2004). Soils and archaeology research. Oxford University Press, Oxford.

Ingold, T. (2000). The perception of the environment. Essays in livelihood, dwelling and skill, Routledge, Londres/ Nueva York.

Knapp, B. y W. Ashmore (1999). Archaeological landscapes: constructed, conceptualized, ideational, en: W. Ashmore y B. Knapp, Archaeologies of Landscape: contemporary perspectives, 1-30, Blackwell, Massachussets/ Oxford.

Ledru, M.P., G. Ceccantini, S. E. M Gouveia, J. A. López-Sáez, L. C. R. Pessenda y A. S. Ribeiro (2006). MillenialScale Climatic and Vegetation Changes, en: A northern Cerrado (northeast, Brazil) since the Last Glacial Maximum. Quaternary Science Reviews 25 (9-10), 1110-1126. 
Ledru. M.P. (2002). Late Quaternary history and evolution of the Cerrados as revealed by palynological records. En: P. S. Oliveira y R. J. Marquis (eds.), Os Cerrados do Brasil: Ecologia e História Natural de uma Savana Neotropical, 33-50, Columbia University Press, Nueva York.

Lee, R. B. (1979). The !Kung San: men, women and work in a foraging society, Cambridge University Press, Cambridge.

Lee, R. B. y I. De Vore (eds.) (1976). Kalahari Hunter Gatherers. Studies of the !Kung San and their neighbors, Harvard University Press, Cambridge.

Lima, A. P. G. (2016). Patrimônio Arqueológico de Serranópolis/GO: reflexöes para a busca de uma tutela compartilhada e efetiva, tesis de doctorado en Arqueología, Museu de Arqueologia e Etnologia, Universidade de São Paulo, São Paulo.

Lino, J. T. (2012). A arqueologia da paisagem como enfoque teórico para o estudo arqueológico da guerra do Contestado, Revista Tempos Acadêmicos 10, 58-67.

Little, P. E. (2002). Territórios sociais e povos tradicionais no Brasil: por uma antropologia da territorialidade, Anuário Antropológico 28 (1), 251-290.

Lourdeau, A. (2010). Le technocomplexe Itaparica: Définition techno-fonctionnelle des industries à pièces façonnées unifacialement à une face plane dans le centre et le nord-est du Brésil pendant la transition Pléistocène-Holocène et l'Holocène ancien, tesis de doctorado en Arqueología, Université Paris Ouest Nanterre La Défense, Paris.

Mamede, L. (1996). O significado das coberturas terciárias nas chapadas da regiáo Centro-Oeste, I Simpósio Nacional de Geomorfologia, Sociedade \& Natureza, Uberlândia 8 (15), 26-30.

Martínez, G. A. (1999). Tecnología, subsistencia y asentamiento en el curso medio del río Quequén Grande: un enfoque arqueológico, tesis de doctorado en Arqueología, Facultad de Ciencias Naturales y Museo, Universidad Nacional de La Plata, La Plata.

Martins, D. C. (coord.) (2010). Diagnóstico, mapeamento e elaboração de diretrizes de gestão dos sitios arqueológicos do Grupo A, município de Serranópolis/GO, Instituto do Patrimônio Histórico e Artístico Nacional, Universidade Federal de Goiás, Goiânia.

Morais, J. L. de (1999). A Arqueologia e o fator geo, Revista do Museu de Arqueologia e Etnologia 9, 3-22.

Moura, E. C. (2019). Apropriação e construção da paisagem no contexto do sítio arqueológico GO-JA-02, Serranópolis-Goiás, tesis de pregrado en arqueología, Instituto Goiano de Pré-História e Antropologia, Pontifícia Universidade Católica de Goiás, Goiânia.

Nascimento, J. B. (2012). Análise dos principais condicionantes naturais e antrópicos de destruição dos registros rupestres de Serranópolis, Goiás, tesis de pregrado en Arqueología, Instituto Goiano de Pré-História e Antropologia, PUC-Goiás, Goiânia.

Neves, E. G. (2006). Arqueologia amazônica, Jorge Zahar, Rio de Janeiro.

Nogueira, R. S. (2015). Arqueologia da paisagem, Serranópolis na interpretação dos espaços sociais, Habitus 13 (1), 89-112.

Nogueira, R. S. (2013). A construção do Patrimônio Arqueológico em Serranópolis, Goiás, tesis de maestría en Historia, Pontifícia Universidade Católica de Goiás, Goiânia.

Ogot, B. A. (ed.) (1999). Africa from the sixteenth to the eighteenth century, General History of Africa, vol. V, Unesco, Heinemann International Literature and Textbooks, University of California Press, Paris/Oxford/ California.

Oliveira, A. M. S. (1990). Depósitos tecnogênicos associados à erosão atual, Actas del VI Congresso Brasileiro de Geologia de Engenharia y IX Congresso Brasileiro de Mecânica dos Solos e Engenharia de Fundaçôes, 411-415, São Paulo.

Oliveira, A. M. S. (1994). Depósitos tecnogênicos e assoreamento de reservatórios: exemplo do reservatório de Capivara, Rio Paranapanema SP/PR, I y II, tesis de doctorado, Faculdade de Filosofia, Letras e Ciências Humanas, Universidade de São Paulo, São Paulo.

Oliveira, A. M. S. y J. J. Monticeli (eds.) (2018). Geologia de engenharia e ambiental, métodos e técnicas, II, Métodos y Técnicas, Associação Brasileira de Geologia de Engenharia e Ambiental, São Paulo.

Oliveira, K. G. (2019). Diversidades tecnológicas dos instrumentos líticos da transiçẫo do Pleistoceno/Holoceno Antigo - sítio GO-JA-01 - Serranópolis, tesis de pregrado en Arqueología, Pontifícia Universidade Católica de Goiás, Goiás.

Oliveira, R. M. y M. L. Souza (2009). Estudos para Chancela de paisagem cultural: diagnóstico arqueológico dos Núcleos B, C, E, F georeferenciamento de sítios arqueológicos no município de Serranópolis, Goiás, Instituto do Patrimônio Histórico e Artístico Nacional, Instituto de Desenvolvimento Tecnológico do Centro-Oeste, Goiânia.

Pellini, J. R. (2014). Paisagens: práticas, memórias e narrativas, Habitus 12 (1), 125-142. 
Peloggia, A. U. G., A. M. S. Oliveira, A. A. Oliveira, E. C.N. Silva y J. O. R. Nunes (2014). Technogenic geodiversity: a proposal on the classification as artificial ground, Quaternary and Environmental Geosciences 5 (1), 28-40.

Peloggia, A. U.G. (2017). O que produzimos sob nossos pés? Uma revisão comparativa dos conceitos fundamentais referentes a solos e terrenos antropogênicos, Revista UNG - Geociências 16 (1), 102-127.

Peña Monné, J. L., M. M. Sampietro Vattuone, M. G. Maldonado, S. F. Cano y M. G. Aguirre (2016). Contexto geomorfológico y problemas de conservación en el sitio arqueológico El Pichao (valle de Santa María, noroeste Argentino), en: M. M. Sampietro Vattuone y J. L. Peña Monné (eds.), Geoarqueología de los valles Calchaquies, 185-184, Universidad Nacional de Tucumán, Tucumán,

Pereira, E., C. D. R. Carneiro, S. Bergamaschi y F. F. M.Almeida (2012). Evolução das sinéclises paleozoicas: províncias Solimóes, Amazonas, Parnaíba e Paraná, en: Y. Hasui, C. D. R. Carneiro, F. F. M. Almeida y A. Bartorelli (orgs.), Geologia do Brasil, 374-394, Editorial Beca, São Paulo.

Procedino, P. M. O. A. (2019). Formação e preservaçáo do registro arqueológico: processos naturais-culturais no sítio GO-JA-02, Serranópolis, Goiás, tesis de pregrado en Arqueología, Instituto Goiano de Pré-História e Antropologia, Pontifícia Universidade Católica de Goiás, Goiânia.

Ramos, M. P. de M. (2016). As indústrias líticas do Holoceno médio no sítio GO-JA-01: uma reavaliação a partir da abordagem tecnofuncional, tesis de pregrado en Arqueología, Instituto Goiano de Pré-História e Antropologia, Pontifícia Universidade Católica de Goiás, Goiânia.

Ramos, M. P. M y S. A. Viana (2019). Diagnose tecno-funcional de amostragem lítica datada do início do Holoceno Médio no sítio arqueológico GO-JA-01: características da estrutura de lascamento em presença, Revista Mosaico 12, 135-163.

Ramsey, C. B. (2020). OxCal 4.4 Manual. https://c14.arch.ox.ac.uk/oxcal/OxCal.html. Septiembre de 2020.

Reatto, A., J. R. Correia y S. T. Spera (2008). Solos do Bioma Cerrado: aspectos pedológicos, en: S. M. Sano, S. P. de Almeida y J. F. Ribeiro (eds.), Cerrado: ecologia e flora, 107-149, Embrapa, Brasilia.

Resende, F. E. C. P. (2017). El pasado y el presente en los refugios rupestres de Serranópolis - Goiás - Brasil - La preservación de herencia informacional, plan de tesis de doctorado, Universidad Nacional del Centro de la Provincia de Buenos Aires, Olavarría.

Resende, F. E. C. P., A. B. Fernandes, J. C. R. de Rubin, M. Barberi, M. E. Bichuette, J. E. Gallão, T. Zepon, S.M. Silva y U. F. Souza (2019). Relatório final das açôes emergenciais de conservaçẫo das pinturas e gravuras rupestres nos sitios de abrigos do Complexo Arqueológico de Serranópolis-GO, MRS Estudos Ambientais, Brasilia.

Ribeiro, J. F. y B. M. T. Walter (2008). As principais fitofisionomias do bioma cerrado, en: S. M. Sano, S. P. de Almeida y J. F. Ribeiro (eds.), Cerrado: ecologia e flora, 151-212, Embrapa, Brasilia.

Rodet, M. J., D. Duarte-Talim y P. Schmitz (2019). As indústrias líticas antigas de Serranópolis (sítios GO-JA-03 e GO-JA-14), Revista de Arqueologia 32, 175-206.

Rogge, J. H. (2004). Fenômenos de fronteira: um estudo das situaçöes de contato entre os portadores das tradiçöes cerâmicas pré-históricas no Rio Grande do Sul, tesis de doctorado en História, Universidade do Vale do Rio dos Sinos, São Leopoldo.

Rubin, J. C. R, R. T. da Silva y M. Barberi (2016). Consideraciones al respecto del contexto arqueológico: Serranópolis, Goiás (Brasil), en: C. López y M. C. Cano (comps), El poblamiento temprano en América, Serie Prehistoria en América, 320-328, Museo del Desierto, Ciudad de México.

Rubin, J. C. R, R. T. da Silva, C. Barreto y L. M. Vaz (2015). Transformaçōes na paisagem por grupos pré-coloniais, Goiás, Brasil, en: J. C. R. Rubin, C. M. Favier-Dubois y R. T. Silva (orgs.), Geoarqueologia na América do Sul, 141-168, PUC Goiás, Goiânia.

Rubin, J. C. R. (2017). Escavaçẫo do sítio arqueológico GO-JA-02, Serranópolis, Goiás, PUC-Goiás, Goiânia.

Rubin, J. C. R. y R. T. da Silva (2006). Programa Patrimônio Arqueológico Histórico-Cultural AHE-Espora, Levantamento do Potencial Arqueológico da Area Diretamente Afetada, relatório técnico, Lithotec Consultoria e Assessoria, Goiânia.

Rubin, J. C. R., F. J.C. de Lorenzo, R. T. da Silva y D. S. Correa (2017). Efeitos da erosão e sítios arqueológicos no estado de Goiás: casos de Serranópolis e Palestina de Goiás, Clio Arqueológica 32 (1), 37-67.

Rubin, J. C. R., M. A. Telles, E. Teixeira, R. T. Silva y S. A. Viana (2018). Revisitando o sítio arqueológico casa da Pedra, Serranópolis, Goiás, Anais VI Grupo de estudos Geoaqueologia da América Latina, 22, Ubajara.

Rubin, J. C. R., M. Barberi, R. T. da Silva, A. R. Saad, G. V. Garcia y C. M. Lemos. (2011). Arqueologia e paleoambiente. Habitus, Goiânia 9 (11), 49- 59.

Rubin, J. C. R., R. T. Silva, R. Najjar, C. M. Ferreira y G. V. Garcia (2019). Geoarchaeology and historical archaeology in Pelourinho, Salvador, Brazil: settlement, landscape, and hypotheses, en: H. Inda Ferrero y F. García 
Rodríguez (eds.), Advances in Coastal Geoarchaeology in Latin America, 49-64, The Latin American Studies Book Series, Springer, Cham.

Rubin, J. C.R. (2003). Sedimentação quaternária, contexto paleoambiental e interação antrópica nos depósitos aluviais do Alto rio Meia Ponte - Goiás/GO, tesis de doctorado de geociências, Universidade Estadual Paulista, Río Claro.

Saldanha, J. D. M. (2016). Poços, potes e pedras: uma longa história indígena na costa da Guayana, tesis de doctorado en Arqueología, Museu de Arqueologia e Etnologia, Universidade de São Paulo, São Paulo.

Salgado-Labouriau, M. L., V. Casseti, K. Ferraz-Vicentini, L. Martin, F. Soubiés, K. Suguio y B.Turcq (1997). Late Quaternary vegetational and climatic changes in cerrado and palm swamp from Central Brazil. Palaeogeography, Palaeoclimatology, Palaeoecology 128 (1-4), 215-226.

Sampietro-Vattuone, M. M. y J. L. Peña Monné (2016). Geomorphological dynamic changes during the Holocene through ephemeral stream analyses from Northwest Argentina, Catena 147, 663-677.

Sampietro-Vattuone, M. M. y J. L. Peña Monné (2019). Geomorphology of Tafi valley (Tucumán Province, Northwest Argentina), Journal of Maps 15 (2), 1-8.

Sanjuán, L. G. (2005). Introducción al reconocimiento y análisis arqueológico del territorio, Ariel Prehistoria, Barcelona.

Santos, H. G. dos, P. K.T. Jacomine, L. H. C. dos Anjos, V. A. de Oliveira, J. F. Lumbreras, M. R. Coelho, J. A. de Almeida, J. C. de A. Filho, J. B. de Oliveira y T. J.F. Cunha (2018). Sistema brasileiro de classificação de solos. Embrapa, Brasília.

Schaan, D. P. (2009). Paisagens, imagens e memórias da Amazônia Pré-Colombiana, en: F. L. A da Silveira y C. D. Cancela (orgs.) Paisagem e Cultura. - dinâmicas do patrimônio e da memória na atualidade, 7-20, EDUFPA, Belém.

Schlanger, S. H. (1992). Recognizing persistent places in Anasazi settlement systems, en: J. Rossignol y L. Wandsnider (eds.), Space, time, and archaeological landscapes: interdisciplinary contributions to archaeology, 91-112, Springer, Boston.

Schmitz, P. I. (1980). A evolução da cultura no Sudoeste de Goiás, Pesquisas. Antropologia 31, 185-225.

Schmitz, P. I. (1987). Caçadores antigos no sudoeste de Goiás, Brasil, Estudios Atacameños 8, 17-37.

Schmitz, P. I. y A. S. Barbosa (1985). Horticultores pré-históricos do estado de Goid́s, Instituto Anchietano de Pesquisas - UNISINOS, São Leopoldo.

Schmitz, P. I., A. O. Rosa y A. L. V. Bitencourt (2004). Arqueologia nos cerrados do Brasil Central, Serranópolis III, Pesquisas. Antropologia 60, 3-286.

Schmitz, P. I., A. S. Barbosa, A. J. Jacobus y M. B. Ribeiro (1989). Arqueologia nos cerrados do Brasil Central, Serranópolis I, Pesquisas. Antropologia 44, 9-208.

Schmitz, P. I., F. A. Silva y M. V. Beber (1997). Arqueologia nos cerrados do Brasil Central, Serranópolis II. As pinturas e gravuras dos abrigos, Instituto Anchietano de Pesquisas, Unisinos, São Leopoldo.

Scopel, I., M. S. Souza, D. M. Peixinho, R. E. Alves, Z. de F. Mariano, D. S. Freitas y P. F. Santos. (2010). Uso e manejo de neossolo quartzarênico em Serranópolis (Goiás/Brasil): grau de degradação e possível recuperação, ponencia presentada al VI Seminário Latino-Americano de Geografia Física, II Seminário Ibero-Americano de Geografia Física, Coimbra.

Shanks, M. y I. Hodder (1995). Processual, postprocessual and interpretative archaeologies, en: C. Tilley (ed.), Interpreting Archaeology: finding meaning in the past, 3-33, Routledge, New York.

Silva, E. B. (2019). Planície aluvial do médio do rio Verde: hipóteses e reflexões, tesis de pregrado en arqueología, Instituto Goiano de Pré-História e Antropologia, Pontifícia Universidade Católica de Goiás, Goiânia.

Silva, E. B., J. C. R. Rubin y E. M. Kashimoto (2020). Principais abordagens arqueológicas em planícies aluviais: um estudo de caso do Rio Verde no município de Serranópolis - Goiás-Brasil, Revista Cadernos do CEOM Antropoceno 33 (52), 50-60.

Silva, F.A.M. da, E. D. Assad y B. A. Evangelista (2008). Caracterização Climática do Bioma Cerrado, en: S. M. Sano, S. P. de Almeida y J. F. Ribeiro (eds.), Cerrado: ecologia e flora, 71-88, Embrapa, Brasilia.

Simpson, L.A. y J. H. Barret (1996). Interpretation of midden formation processes at Robert's Haven, Caithness, Scotland using thin section micromorphology, Journal of Archaeological Science 23 (4), 543-556.

Souza, H. A. (2005). O desgaste da pintura rupestre e dos abrigos sob rocha na Reserva Particular do Patrimônio Natural (RPPN) Pousada das Araras em Serranópolis: condicionantes naturais, tesis de maestría en Arqueología, Pontifícia Universidade Católica de Goiás, Goiânia.

Souza, M. G. (2020). Análise macrorregional do Complexo de Sítios Arqueológicos de Serranópolis: relação e interação entre paisagem e caçadores-coletores, tesis de pregrado en arqueología, Instituto Goiano de Pré-História e Antropologia, Pontifícia Universidade Católica de Goiás, Goiânia. 
Stein, J. (1983). Earthworm activity: a source of potential disturbance of archaeological sediments, American Antiquity 28 (2), 277-289.

Tchilinguirián, P., I. Ozán I. y M. Morales (2016). El suelo y la arqueología, en: F. Pereira y M. Torres Duggan (eds.), Suelos y geología argentina, una visión integradora desde diferentes campos disciplinarios, 252-276. Asociación Geológica Argentina, Asociación Argentina Ciencia del Suelo, UNDAV Ediciones, Buenos Aires/Avellaneda.

Tilley, C. (2014). Do corpo ao lugar à paisagem: uma perspectiva fenomenológica, Vestígios. Revista LatinoAmericana de Arqueologia Histórica 8 (1), 21-62.

Tilley, C. A. (1994). Phenomenology of landscape, places, paths and monuments, Berg Publishers, Oxford.

Vasconcelos, P. M. (1996). Paleoclimas e evolução geomorfológica da região de Carajás: evidência geoquímica e geocronológica, Actas del V Simposio de Geología Amazónica, 26-30, Belém.

Viana, S. A. (2016). Repensando os povoamentos no Planalto Central do Brasil a partir da regiáo de Serranópolis, PUC Goiás, Goiânia.

Viana, S. A. y S. Hoeltz (e.p.). Technicities in the early holocene: brazilian hinterlands and the bolivian chaco, Brasil,

Villafañez, E. A. (2012). Arqueología, senderos y paisaje en el valle de Balcosna, Revista de Jóvenes Investigadores en Arqueología 8 (2), 119-136.

Villagran, X. S. (2010). Estratigrafias que falam: geoarqueologia de um sambaqui monumental, Annablume Editora, São Paulo.

Willey, G. (1953). Prehistoric Settlement Patterns in the Viru Valley, Bureau of American Ethnology Bulletin, Washington, D.C.

Recibido: junio 2020

Aceptado: octubre 2020 